\title{
How does the connectivity between populations mediate range limits of marine invertebrates? A case study of larval dispersal between the Bay of Biscay and the English Channel (North-East Atlantic)
}

\author{
Sakina-Dorothée Ayata ${ }^{\mathrm{a}, \mathrm{b}, *}$, Pascal Lazure ${ }^{\mathrm{c}}$, Éric Thiébaut ${ }^{\mathrm{a}, \mathrm{b}}$ \\ a Université Pierre \& Marie Curie, Station Biologique de Roscoff, Laboratoire 'Adaptation et diversité en milieu marin', F-29682 Roscoff cedex, France \\ ${ }^{\mathrm{b}}$ CNRS, UMR 7144, Laboratoire 'Adaptation et diversité en milieu marin', F-29682, Roscoff cedex, France \\ 'Ifremer, Département 'Dynamiques de l'Environnement Côtier', BP 70, F-29280 Plouzané, France
}

\section{A R T I C L E I N F O}

Article history:

Available online 29 September 2010

\begin{abstract}
A B S T R A C T
For many marine species, larval dispersal plays a crucial role in population persistence, re-colonization of disturbed areas, and distribution of species range limits through the control of population connectivity. Along the French Atlantic coast (NE Atlantic), a biogeographical transition zone has been reported between temperate and cold-temperate marine faunal assemblages. Hydrodynamics in this area are highly complex and variable including numerous mesoscale features (e.g. river plumes, fronts, upwellings, low salinity lenses), which could constrain larval transport and connectivity. In this context, the aim of this study was to assess how hydrodynamic conditions and biological traits influence larval transport and contribute to population connectivity along the biogeographical transition zone between the Bay of Biscay and the English Channel. A coupled bio-physical individual-based model was used at a regional scale to track larval trajectories under realistic hydroclimatic conditions (tides, river run-offs, and meteorological conditions) and for some common life-history traits. Larval particles were released monthly from February to August for the years 2001 to 2005, from 16 spawning populations corresponding to the main bays and estuaries of the study area. Two planktonic larval durations ( 2 vs. 4 weeks) and three vertical distributions (no swimming behaviour, diel vertical migration, and ontogenic vertical migration) were considered. Dispersal kernels were described by 17 parameters and analysed in a multivariate approach to calculate connectivity matrices and indices. The main factors responsible for the variability of the dispersal kernels were the spawning month in relation to the seasonal variations in river run-offs and wind conditions, the planktonic larval duration, the spawning population location, and the larval behaviour. No significant inter-annual variability was observed. Self-retention rates were high and larval exchanges occurred mainly within the main hydrodynamical areas: the western English Channel, the Southern Brittany, and the Central Bay of Biscay. Connectivity between the English Channel and the Bay of Biscay populations was low and occurred only under particular hydroclimatic conditions (i.e. high river run-off and strong SW winds) and for some biological traits (i.e. long planktonic larval duration).
\end{abstract}

(c) 2010 Elsevier Ltd. All rights reserved.

\section{Introduction}

Connectivity, defined by Cowen et al. (2007) as the "exchange of individuals among geographically separated subpopulations that comprise a metapopulation", is a crucial process for the dynamics of marine populations and metapopulations. For most benthic organisms with complex life cycles, connectivity is assured through the release of pelagic larvae, the transport of those larvae by ocean currents in interaction with larval behaviour, and the settlement and the metamorphosis of competent larvae into benthic juveniles

\footnotetext{
* Corresponding author at: Université Pierre \& Marie Curie, Station Biologique de Roscoff, Laboratoire 'Adaptation et diversité en milieu marin', F-29682 Roscoff cedex, France. Tel.: +33 (0)2 982925 31; fax: +33 (0)2 98292324

E-mail address: sakina.ayata@normalesup.org (S.-D. Ayata).
}

(Pineda et al., 2007). Thus, larval dispersal plays a crucial role in connectivity and its success has tremendous ecological consequences in local population persistence, re-colonization of disturbed areas, spreading of invasive species and range limits of species distributions (Levin, 2006; Cowen and Sponaugle, 2009).

Range limits of marine species often co-localize with hydrological discontinuities, where water masses with different physical properties, such as temperature, come into contact. It has been traditionally assumed that the physiological constraints imposed by those sudden changes in environmental parameters were responsible for the localization of range limits of marine species at oceanographic discontinuities (Suchanek et al., 1997). However, Gaylord and Gaines (2000) have demonstrated that discontinuities in ocean flow fields could be sufficient to restrict larval dispersal and determine the distribution of marine species. Based on a 
coupled population dynamics-dispersal model, their results suggested that the common hydrodynamical features usually observed at biogeographical boundaries (e.g. convergent circulation, divergent circulation, eddies) could function as one- or two-way barriers to dispersal with variable permeability, depending on life-history traits and hydrodynamic variability. For example, in the North-East Pacific at Point Conception, a major biogeographical boundary coincident with the range limits for many marine taxa, the recent extension of the northern range limit of the marine gastropod Kelletia kelletii was partly imputed to modifications in coastal circulation (Zacherl et al., 2003).

In the North-East Atlantic Ocean, the Ushant Sea ("mer d'Iroise") has been described as a biogeographical transition zone between the temperate and cold-temperate marine assemblages (Lusitanian province in the south and Boreal province in the north; Cox and Moore, 2000; Dinter, 2001). Furthermore, phylogeographic discontinuities have been recently reported between the Bay of Biscay and the English Channel populations of different benthic invertebrates, including the polychaetes Pectinaria koreni and Owenia fusiformis (Jolly et al., 2005; Jolly et al., 2006). A complex frontal system has been described in the Ushant Sea (Pingree et al., 1975; Mariette and Le Cann, 1985; Le Boyer et al., 2009) that could constrain larval transport and connectivity between the Bay of Biscay and the English Channel (Le Fèvre, 1986). However, intrusions of low salinity waters from the Bay of Biscay have been reported at the entrance of the English Channel (Kelly-Gerreyn et al., 2006), suggesting a possible transport of water from the Bay of Biscay to the western English Channel under particular hydroclimatic conditions. Low salinity intrusions resulted from: (1) north-westwards transport of plume waters from the Loire and Gironde rivers, favoured by high run-off and NE winds and (2) eastwards transport into the western English Channel under SW/SE winds. On the other hand, the hydrodynamics of the Bay of Biscay are highly complex and variable (Koutsikopoulos and Le Cann, 1996) with numerous mesoscale structures, such as river plumes, low salinity lenses, fronts and upwellings (Puillat et al., 2004, 2006). All those mesoscale structures are known to greatly affect larval dispersal or retention (Shanks et al., 2002, 2003) and consequently connectivity.

The study of larval dispersal and connectivity in marine environments is challenging because pelagic larvae are numerous and small, from a few hundred microns for invertebrate larvae to a few centimetres for fish larvae, making them difficult to track in situ. Recently, progress has been made in the study of larval dispersal and connectivity, including genetic approaches, chemical tracking such as trace elemental fingerprinting, and coupled bio-physical modelling (Levin, 2006; Cowen and Sponaugle, 2009; Metaxas and Saunders, 2009). Using individual-based models (IBM), the trajectories of a large number of particles can be tracked in theoretical or realistic hydrodynamical fields. Particles can be described in a first approximation with very simple biological parameters to depict their larval life span or their vertical distribution (Aiken et al., 2007; Edwards et al., 2007; Marinone et al., 2008) or, when known, with speciesspecific biological traits (North et al., 2008). Here, a 3-dimensional bio-physical model was used to describe larval dispersal and connectivity of benthic invertebrates inhabiting fragmented habitats in the western English Channel and in the Bay of Biscay. The hydrodynamic model was forced by realistic hydroclimatic conditions while larval biology was kept as simple as possible in the biological model, using common life-history traits of benthic invertebrates in temperate regions (spawnings from February to August, common larval swimming behaviours, planktonic larval durations of 2 or 4 weeks). Our goal was then to build a generic model of larval dispersal of benthic invertebrates with common life history characteristics inhabiting the fragmented habitat of the study area.

In this context, the present study focused on the larval dispersal and connectivity of benthic invertebrates in the North-East
Atlantic, in order to: (1) assess the relative roles played by hydroclimatic variability and biological traits in larval transport and connectivity patterns in the Bay of Biscay and in the western English Channel and (2) determine if and when connectivity could be possible from the Bay of Biscay to the English Channel populations, i.e. through the Ushant frontal system. Eventually, the aim of the present work was to answer the following question: how does the connectivity between populations mediate range limits of marine invertebrates in the North-East Atlantic?

\section{Methods}

\subsection{Study area: hydrodynamic and hydrological characteristics}

In the English Channel, tides dominate the transport regime eastwards (Fig. 1A) and are responsible for $60 \%$ of the long-term residual flow (Pingree and Maddock, 1977), although this long-term flow can be reversed from east to west by strong northern winds (Salomon and Breton, 1993). Conversely, tidal influence is weak over the continental shelf of the Bay of Biscay where the circulation mainly depends on winds and horizontal density gradients and exhibits strong seasonal variations (Fig. 1A) (Koutsikopoulos and Le Cann, 1996).

The Bay of Biscay receives strong freshwater run-off from the Vilaine, the Loire, the Gironde, and the Adour, with maximum river discharges in winter and spring (Fig. 1A). From January to the beginning of April, the water column is homogeneous, except in the vicinity of estuaries and coastal areas where strong run-off, combined with relatively low vertical mixing, can cause strong haline stratification. Thermal stratification appears in April in the western coastal zone of the bay or in May over the continental shelf, and occurs until mid-September, with maximal vertical temperature differences between surface and bottom layers of $9-10{ }^{\circ} \mathrm{C}$.

In the vicinity of the Loire and Gironde estuaries, the presence of low salinity surface waters (LSSW) in spring induces significant density gradients responsible for strong density currents over the shelf $\left(2-20 \mathrm{~cm} \mathrm{~s}^{-1}\right)$, generally oriented northwards. Over the continental shelf, wind-induced currents are highly variable in direction and speed at temporal scales from day to season, although a general wind-induced circulation parallel to the isobaths can be observed. The response of shelf water to steady wind stress is relatively rapid (Pingree and Le Cann, 1989), and in the north of the bay, wind-induced currents usually reach $10 \mathrm{~cm} \mathrm{~s}^{-1}$ to $20-30 \mathrm{~cm} \mathrm{~s}^{-1}$ locally (Koutsikopoulos and Le Cann, 1996). From spring to late summer, NW winds are dominant and induce local upwellings, whereas from autumn to early spring SW winds prevail (Puillat et al., 2006). Furthermore, lower salinity lenses of $50-80 \mathrm{~km}$ wide and about $30 \mathrm{~m}$ thick have been reported over the shelf during $\mathrm{W}$ to $\mathrm{N}$ wind events (Puillat et al., 2006).

In the English Channel, the water column is well mixed all year because of strong tidal mixing and low river run-off, except at its western entrance where a seasonal stratification can be observed (Salomon and Breton, 1993). Strong thermal fronts are caused in the Ushant Sea by tidal mixing in spring and summer (Pingree et al., 1975; Morin et al., 1991; Le Boyer et al., 2009). Low salinity waters from the Loire and Gironde have been reported in the Ushant Sea in early spring (March-April) in 2002, 2003, and 2004, with fastest travel under NE winds (Kelly-Gerreyn et al., 2006), suggesting that the northwards transport of plume waters from the Bay of Biscay to the Ushant Sea may be a common phenomenon.

\subsection{Hydrodynamic model}

The three-dimensional (3D) hydrodynamic model MARS (Model for Applications at Regional Scale, Lazure and Dumas, 2008) was 

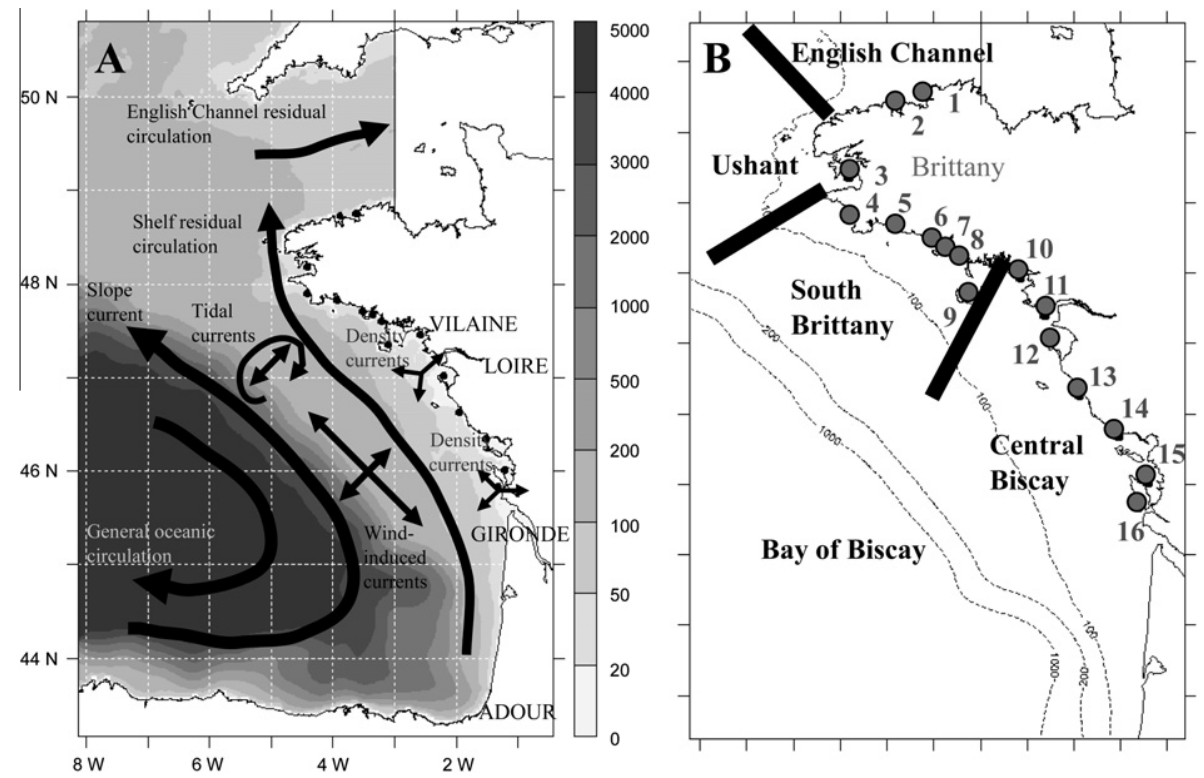

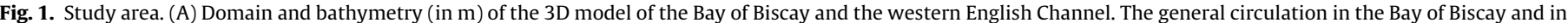

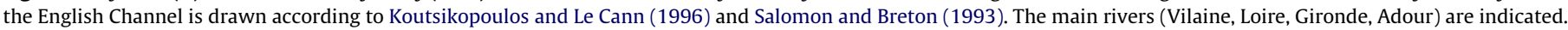

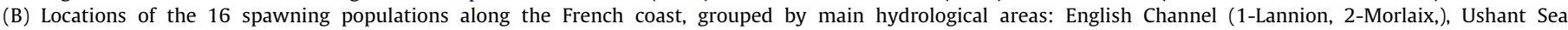

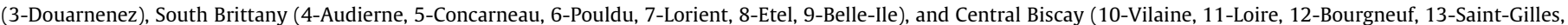
14-Ile de Ré, 15-Antioche, 16-Oléron).

used to simulate the circulation in the study area. It is a finite difference, mode splitting model in a sigma-coordinate framework. The MARS-3D model has been validated in the Bay of Biscay from survey data and satellite observations of currents, salinity, and temperature (Lazure and Jégou, 1998; Lazure and Dumas, 2008; Lazure et al., 2009). It has already been successfully applied to study the transport of fish larvae (Allain et al., 2007; Huret et al., 2010) and toxic phytoplankton (Xie et al., 2007).

In the present study, the model version 6.16 was used with the configuration 'extended Bay of Biscay', whose domain extends from the Spanish coast to $50^{\circ} 30^{\prime} \mathrm{N}$ in latitude and from $08^{\circ} \mathrm{W}$ to the French coast in longitude, with an open eastern boundary in the English Channel fixed at $03^{\circ} 05^{\prime} \mathrm{W}$ (Fig. 1A). The horizontal grid is regular with a mesh size of $4 \mathrm{~km}$. Thirty sigma levels (i.e. terrainfollowing coordinates) are used, with thinner layers near the surface, such as for a $100 \mathrm{~m}$ water column the vertical grid spacing corresponds to a resolution of $0.1 \mathrm{~m}$ at the surface and $4.5 \mathrm{~m}$ in the middle of the column and below. The coastline and bathymetry were provided by the SHOM (Hydrological and Oceanographic Service of the French Navy) with a resolution of $1 / 25,000$. The time step was adaptive and varied from 200 to $400 \mathrm{~s}$.

The open boundary conditions (i.e. free surface elevations) were obtained from a larger barotropic two-dimensional (2D) model of the NW European continental shelf extending from Portugal to Iceland $\left(40^{\circ} \mathrm{N}-65^{\circ} \mathrm{N}, 20^{\circ} \mathrm{W}-15^{\circ} \mathrm{E}\right)$, with a horizontal resolution of $5.6 \mathrm{~km}$. This 2D model was forced by the FES2004 solution (Lyard et al., 2006) which provides 14 tidal components (i.e. M2, S2, K2, N2, 2N2, 01, K1, P1, Q1, Mf, Mtm, Mm, Msqm, and M4). For the two nested models, surface wind stress and pressure, air temperature, nebulosity, and relative humidity were provided by the meteorological ARPEGE model from Météo France. This regional model is centred above France with a spatial resolution of $0.5^{\circ}$ in longitude and latitude. It gives four analysed wind and pressure fields per day assimilating recorded data. Temperature and salinity conditions at the open boundaries were obtained from Reynaud's monthly climatology (Reynaud et al., 1998). Initial conditions in temperature, salinity, and velocity fields were given after a 1-year spin-up simulation. Discharges of the four main rivers (i.e. the Vilaine, the Loire, the Gironde, and the Adour) were obtained from historical time series at daily frequency provided by the French freshwater office database (http://www.hydro.eaufrance.fr/).

\subsection{Particle tracking algorithm}

Particle trajectories were calculated in three dimensions for each time step from the velocity fields calculated on-line by the hydrodynamic model and using the diffusion scheme described by Visser (1997). The Lagrangian trajectories are obtained from: (1) the Eulerian velocity fields and classical Runge-Kutta advection scheme, (2) a random walk process based on the vertical turbulent eddy diffusivity field (Hunter et al., 1993; Visser, 1997), and (3) vertical swimming velocities. Hence, the particle positions are computed at each time step of the hydrodynamic model using the following equations adapted in a sigma coordinate system:

$x_{t+\Delta t}=x_{t}+u(x, y, \sigma, t) \Delta t$

$y_{t+\Delta t}=y_{t}+v(x, y, \sigma, t) \Delta t$

$\sigma_{t+\Delta t}=\sigma_{t}+w(x, y, \sigma, t) \Delta t+R_{w}\left(\sigma_{t}, \Delta t, K_{\sigma}\right)+w_{p} \Delta t$

with $\left(x_{t}, y_{t}, \sigma_{t}\right)$ the particle coordinates in the sigma framework at the time $t,(u, v, w)$ the velocity field linearly interpolated at the position $\left(x_{t}, y_{t}, \sigma_{t}\right)$ and obtained from the 3D hydrodynamic model, $\Delta t$ the model time step, $R_{w}$ a non-naive random walk function (Visser, 1997 ), $K_{\sigma}$ the vertical eddy diffusivity (also obtained from the 3D model), and $w_{p}$ the particle swimming velocity (see Section 2.4.).

In the sigma framework, the particle sigma depth is equal to zero at the bottom $\left(\sigma_{t}=0\right)$ and to one at the surface $\left(\sigma_{t}=1\right) . R_{w}$ is given by the sum of random displacements $d_{\delta t}\left(\sigma_{t}\right)$ obtained on $n_{d t z}$ sub-loops with a smaller time step $\delta t=\Delta t / n_{d t z}$ (Ross and Sharples, 2004; North et al., 2006) such as:

$$
\begin{aligned}
& R_{w}\left(\sigma_{t}, \Delta t, K_{\sigma}\right)=\sum_{n=1}^{n=n_{d t z}} d_{\delta t}\left(\sigma_{t}, K_{\sigma}\right) \\
& d_{\delta t}\left(\sigma_{t}, K_{\sigma}\right)=\frac{\partial K_{\sigma}}{\partial \sigma} \delta t+R \sqrt{2 r^{-1} K_{\sigma}\left(\sigma_{t}+\frac{1}{2} K_{\sigma}^{\prime} \delta t\right) \delta t}
\end{aligned}
$$


with $R$ a random process with a mean equal to zero and a variance $r$ equal to one, here a uniform deviate given by the Fortran 90 random number generator. The number of sub-loops of the random walk process has been fixed at $n_{d t z}=200$, leading to a random walk time step $\delta t$ ranging from 1 to $2 \mathrm{~s}$. Ross and Sharples (2004) underlined that both $K_{\sigma}^{\prime}$ and $K_{\sigma}^{\prime \prime}$ need to be continuous and differentiable to avoid artificial particle accumulation. This criterion is ensured for a sufficiently small time-step:

$\delta t \ll M I N \frac{1}{\left|K_{\sigma}^{\prime \prime}\right|}$

which is verified for a random walk time step $\delta t$ ranging from 1 to $2 \mathrm{~s}$.

As done in previous studies on larval dispersal in the Bay of Biscay (Allain et al., 2007; Huret et al., 2010), no horizontal diffusion was included in the transport model for several reasons. First, horizontal diffusion in the oceans is mainly governed by vertical gradients combined with vertical eddy diffusivity (Houghton, 2002). Second, although turbulence has been shown to have important consequences for dispersal in some coastal areas (Guizien et al., 2006), on continental shelves under the influence of tides and wind-induced circulation like those of the study area, Proehl et al. (2005) have shown that the horizontal diffusion could be neglected in Lagrangian transport models. Off North Carolina, Kuebel Cervantes et al. (2003) have also demonstrated that the horizontal diffusion under the effect of winds is an order of magnitude smaller than the effect of vertical diffusion. Third, specifically in the Bay of Biscay, drifter tracking experiments have shown the dominance of advective movements due to tides, winds and density gradients over diffusive motion (Lazure et al., 2008), suggesting that the importance of horizontal turbulence on larval dispersal is of secondary order.

As usually fixed for larval dispersal models, the top and bottom boundaries as well as coastal boundaries are reflecting boundaries.

\subsection{Generic individual-based model of invertebrate larvae}

To simulate the transport of planktonic larvae of near shore invertebrates inhabiting fragmented habitats, a generic Lagrangian model was designed for typical benthic invertebrates inhabiting muddy fine sand sediments. Larval particles were released from 16 spawning populations (Fig. 1B) along the French Atlantic coast corresponding to the main bays and estuaries of the study area where coastal invertebrates confined to muddy fine sand sediments were reported (Cabioch, 1968; Glémarec, 1969; Hily, 1976; Guillou, 1980). Those 16 spawning populations can be grouped in four main hydrological areas (Fig. 1B): (1) two populations in North Brittany/ western English Channel (Lannion, Morlaix), (2) one population in the Ushant Sea (Douarnenez), (3) six populations in South Brittany, i.e. where the coastline is oriented NW-SE (Audierne, Concarneau, Pouldu, Lorient, Etel, Belle-Ile), and (4) seven populations in Central
Bay of Biscay, i.e. where the coastline is oriented N-S and where the estuaries of the main rivers are located (Vilaine, Loire, Bourgneuf, Saint-Gilles, Ile de Ré, Antioche, Oléron). Since initial particle depth did not alter dispersal patterns (data not shown) and since eggs are usually positively buoyant, particles were arbitrarily released at $5 \mathrm{~m}$ depth, centered above the grid cell of the spawning population. Spawnings were simulated monthly, from February to August, in average tide conditions for the years 2001 to 2005 to cover a wide range of hydrodynamic conditions that can be encountered by larvae released from late winter to summer. These seasons correspond to the usual spawning periods of most benthic invertebrates in temperate regions (Olive, 1995). For each spawning date, 1000 larval particles were released from each spawning population to obtain statistically reliable dispersal patterns.

Simple biological traits were used in this study: a constant planktonic larval duration, a schematic larval behaviour, and no larval mortality. Two values of planktonic larval duration (PLD) were considered: a relatively short PLD of 2 weeks and a relatively long PLD of 4 weeks, which are typical values for marine invertebrates (Kinlan and Gaines, 2003). Particle positions at the end of the PLD were used to calculate the dispersal kernels and connectivity matrices (see Sections 2.6 and 2.8). Since larval vertical swimming behaviour can alter dispersal patterns, even for weakswimming larvae (North et al., 2008), simple larval behaviours were tested to assess their potential role in dispersal patterns and connectivity in the Bay of Biscay. Three vertical larval distributions, commonly reported for marine invertebrate larvae, were then considered: no behaviour (i.e. passive particles) used as a reference case, an ontogenic migration, and a diel migration (Fig. 2). The vertical migrations were computed only for a PLD of 4 weeks. For passive larval particles, the vertical swimming velocity $w_{p}$ was set to 0. Ontogenic swimming behaviour was inspired from the ontogenic swimming velocity scheme proposed by Guizien et al. (2006) for the larvae of the polychaete Owenia fusiformis. Diel vertical migration was computed such as larvae swim downward during the day and upward during the night. Common swimming velocities reported for invertebrate larvae such as polychaetes or bivalves were used (Chia et al., 1984).

\subsection{Numerical experiments}

A first set of simulations was conducted in the absence of larval behaviour to test the role played by the hydrodynamic variability on the larval dispersal and connectivity in the western English Channel and in the Bay of Biscay. For this first set of simulations, the passive dispersal was simulated from the 16 spawning populations for 35 spawning dates ( 7 months, 5 years) with two values of PLD: 1120 dispersal kernels of passive dispersal were obtained. A second set of simulations was realized to test the role played by swimming behaviours on dispersal. For those simulations, larval particles with vertical behaviour (ontogenic migration and diel
A

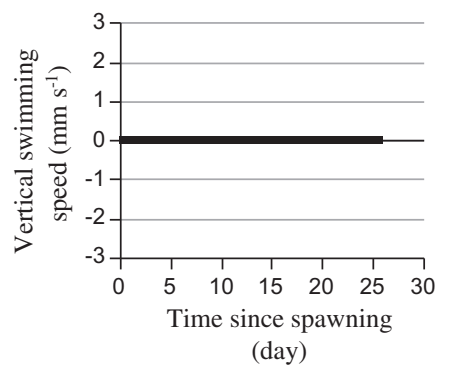

B

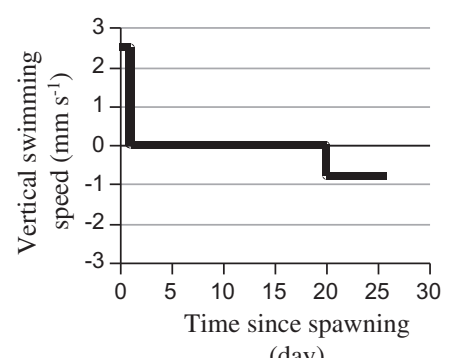

C

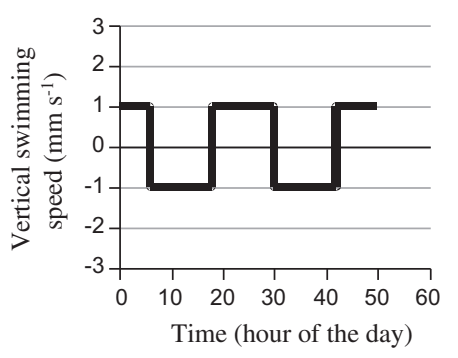

Fig. 2. Temporal evolution of vertical swimming velocities: (A) passive particles, (B) ontogenic migration, and (C) diel migration. 
migration) were released from the 16 spawning populations for seven spawning dates during the year 2003 and the PLD was fixed at 4 weeks; 224 additional dispersal kernels were obtained. Those results were compared with the passive dispersal kernels obtained for the same spawning dates and populations. For this second set of simulations, a total of 336 dispersal kernels were thus analysed.

\subsection{Dispersal kernel descriptors}

To statistically analyze the dispersal patterns, 17 descriptors were defined to describe the 3D dispersal kernels, i.e. the density of larval particles at a given position normalized by the number of particles released. Those 17 dispersal kernel descriptors were modified from the definition of the 2D dispersal kernel given by Edwards et al. (2007) and included:

- mean 3D positions in degree (longitude, latitude) and in sigma coordinate (vertical position), and associated variances and 2Dcovariance: $x_{m}, y_{m}, \sigma_{m}, s_{x}, s_{y}, s_{\sigma}, s_{x y}$,

- mean longitudinal and latitudinal orthodromic dispersal distances calculated from the initial position $\left(x_{0}, y_{0}\right)$ in $\mathrm{km}$, with $R_{e}=6371 \mathrm{~km}$ as the earth radius, and associated variances: $d x_{m}, d y_{m}, s_{d x}, s_{d y}$, with:

$d x_{m}=R_{e}\left(x_{m} \frac{\pi}{180}-x_{0} \frac{\pi}{180}\right)$

$d y_{m}=R_{e}\left(y_{m} \frac{\pi}{180}-y_{0} \frac{\pi}{180}\right)$

- orthodromic distance and direction of the mean 2D position $\left(x_{m}\right.$, $\left.y_{m}\right): d, \theta$, with:

$d=R_{e} \operatorname{acos}\left[\sin \frac{\pi x_{m}}{180} \sin \frac{\pi x_{0}}{180}+\cos \frac{\pi x_{m}}{180} \cos \frac{\pi x_{0}}{180} \cos \left(\frac{\pi y_{m}}{180}-\frac{\pi y_{m}}{180}\right)\right]$

$\theta=\frac{180}{\pi} \operatorname{atan} \frac{y_{m}-y_{0}}{x_{m}-x_{0}} \quad-180\left(y_{m}<y_{0}\right)$

- variance ellipse major axis, minor axis, direction, and isotropy: amaj, amin, $\theta_{m}$, iso,

$a m a j=\sqrt{\frac{1}{2}\left(s_{x}+s_{y}+\sqrt{\left(s_{x}+s_{y}\right)^{2}-4\left(s_{x} s_{y}-s_{x y}^{2}\right)}\right)}$

$\operatorname{amin}=\sqrt{\frac{1}{2}\left(s_{x}+s_{y}-\sqrt{\left(s_{x}+s_{y}\right)^{2}-4\left(s_{x} s_{y}-s_{x y}^{2}\right)}\right)}$

$\theta_{m}=\frac{180}{\pi} \operatorname{atan} \frac{\operatorname{amaj}^{2}-s_{x}}{s_{x y}}$, with $\theta_{m}=90^{\circ}$ if $s_{x y}=0$

$i s o=\frac{a m i n}{a m a j}$

Among those descriptors, Edwards et al. (2007) argued that five are necessary to precisely describe the 2D-dispersal kernels: the dispersal distance and direction ( $d, \theta$, the major and minor axes (amaj, amin) and the direction $\left(\theta_{m}\right)$ of the variance ellipse. However, using all the 17 descriptors described above allowed us to include descriptors on the vertical distribution of the larval particles $\left(\sigma_{m}, s_{\sigma}\right)$ and to take into account their absolute 2Dpositions $\left(x_{m}, y_{m}\right)$. In our case, they correspond to useful descriptors to depict the along-shore/cross-shore transport and the meridional transport between the Bay of Biscay and the English Channel.

\subsection{Redundancy analysis of the dispersal kernel}

For the two sets of simulations, canonical redundancy analyses (RDA) have been conducted on the 17 dispersal kernel descriptors described above. RDA are the direct extension of multiple regression analysis applied to multivariate response data (Legendre and Legendre, 1998). For a given simulation set, we used the matrix of the 17 dispersal kernel descriptors as the table of response variables and the characteristic of the simulations as the table of explanatory variables. For the first set of simulations, the explanatory variables were then: the spawning year, the spawning month, the spawning population, and the PLD. For the second set of simulations, the explanatory variables were: the spawning month, the spawning population, and the swimming behaviour (no behaviour, ontogenic migration, diel migration). The tables of explanatory and response variables were centered and reduced prior to the analysis. To perform the RDA, the rda function of the vegan package version 1.16-8 (http://vegan.r-forge.r-project.org) was used in the R software version 2.6.2 (R Development Core Team, 2005). The significance of the RDA results was tested by permutation tests. Oneway and two-ways analyses of variance (ANOVA) were also performed to test for the significant effects of larval behaviour and spawning month on each dispersal kernel descriptor (aov function of the R software) and on the connectivity size. For each ANOVA, the normality and the homogeneity of variances were verified prior to the analysis. When ANOVA indicated significant differences, a posteriori tests were conducted using the Tukey Honest Significant Differences test (TukeyHSD function of the R software).

\subsection{Connectivity matrices, transport success, and connectivity size}

Connectivity matrices describe the exchange rate between distant populations as the percentage $p_{i j}$ of particles released from one spawning population $j$ (i.e. source population) that settle to an other population $i$ (i.e. sink population) at the end of the PLD. Connectivity matrices are square matrices of rank $n$, with $n$ the number of populations. In the present work, particles were considered to have successfully settled if their final position was located in one of the coastal settlement areas. Settlement areas, representing the patches of the fragmented habitat of fine sand sediments, were defined as the rectangles of $0.21^{\circ}$ in longitude $(\sim 17 \mathrm{~km})$ and $0.15^{\circ}$ in latitude $(\sim 17 \mathrm{~km})$ centred above the 16 spawning populations. Settlement areas were non-overlapping, so that they could be smaller where spawning populations were close to each other, with a minimal size of $0.19^{\circ}$ in longitude and $0.15^{\circ}$ in latitude for the populations \#6 and \#7 (Pouldu and Lorient). The connectivity matrices between the 16 spawning populations were calculated for each spawning date, PLD value, and larval behaviour. For a given PLD and behaviour, monthly-mean connectivity matrices were calculated from the five matrices obtained for the same month for the years 2001-2005.

The transport success (or settlement success) was defined as the percentage of released particles per spawning population that successfully settle. The transport success $T_{j}$ from a spawning population $j$ was given by the sum along columns $j$ of the exchanges rates $p_{i j}$ of the connectivity matrix:

$T_{j}=\sum_{i=1}^{i=n} p_{i j}$

The diagonal of a connectivity matrix gives the self-retention success $\left(p_{i i}\right)$. Since the 16 spawning populations considered here were ordered along a latitudinal gradient along the French Atlantic coast, the exchange rates above the diagonal $\left(p_{i j}\right.$ with $\left.i<j\right)$ corresponded to northward larval transport, whereas the exchange rates below $\left(p_{i j}\right.$ with $i>j$ ) corresponded to southward larval transport. Hence 
the northwards transport success was given by the sum along columns of the exchanges rates above the diagonal $\left(\sum_{i=1}^{i<j} p_{i j}\right)$ whereas the southwards transport success was the sum along columns of the exchanges rates below the diagonal $\left(\sum_{i>j}^{i=n} p_{i j}\right)$. Transport success, self-retention rate, northwards exchange rate and southwards exchange rate were also calculated for each spawning date, i.e. for each connectivity matrix, as the averages of the rates obtained for the 16 spawning populations.

In graph theory, connectivity corresponds to a weighted oriented graph, whose vertices (or nodes) represent populations and directed edges (or arrows) directional exchange rates between populations (Treml et al., 2008). In this context, the total number of connections within a graph, equal to the sums of the adjacency matrix, is the graph's size and is called hereafter the "connectivity size". Connectivity size was then the total number of oriented connections between populations.

\section{Results}

\subsection{Variability of the passive dispersal patterns}

The redundancy analysis conducted on the passive dispersal kernel descriptors against the four explanatory variables (i.e. spawning year, spawning month, spawning populations, PLD), showed that only the first two canonical axes were significant (global $R^{2}=0.1507 ; p<0.005$ ) (Fig. 3). The first axis RDA1 explained $87.5 \%$ of the variance $(p<0.001)$ and was mainly scored by the spawning population and the spawning month. The second axis RDA2 explained only $11.4 \%$ of the variance $(p<0.001)$ and was scored by the PLD and the spawning month. The relative contributions of the explanatory variables to these two axes indicated that the variability of the passive dispersal kernels was mainly due to the spawning population location, the spawning month, and the PLD. The spawning year had no significant effect on the dispersal.
A RDA was also conducted on the five descriptors of the 2Ddispersal kernels proposed by Edwards et al. (2007). Although it showed only one significant axis, similar results were obtained but with a higher contribution of the PLD in the variability of the kernel descriptors (data not shown).

Since no significant inter-annual variation of the dispersal kernels was observed, only the mean trajectories and the average longitudinal and latitudinal distances obtained for the year 2003 are presented to illustrate the influence of the other explanatory variables (Figs. 4 and 5). As indicated by the RDA, mean particle trajectories and distances varied with the spawning location and the spawning month. In the western English Channel, particles released from the two spawning populations of North Brittany were always transported north-eastwards following the English Channel residual circulation (Fig. 4, positive longitudinal and latitudinal distances in Fig. 5A). For these two populations, mean orthodromic distance reached $55 \pm 18 \mathrm{~km}(n=70)$ for a PLD of 4 weeks. In the Ushant Sea, the majority of the particles released from the Bay of Douarnenez (spawning population \#3) were not transported out of the bay whatever the spawning month so that the mean orthodromic distance did not exceed $13 \pm 7 \mathrm{~km}(n=35)$ for a PLD of 4 weeks. Conversely, seasonal patterns were observed for the dispersal of the particles released in South Brittany and in Central Bay of Biscay, in relation to the seasonality of river run-offs and wind conditions. From February to April 2003, mean total runoffs reached $3041 \mathrm{~m}^{3} \mathrm{~s}^{-1}$ in the Bay of Biscay, with SE and SW winds from mid-February to mid-March, then $\mathrm{E}$ winds from midMarch to end of April. During this period, larval trajectories were oriented north-westwards following the coastline (Fig. 4, positive latitudinal and negative longitudinal distances in Fig. 5B and C). From May to August 2003, mean total run-offs decreased to $784 \mathrm{~m}^{3} \mathrm{~s}^{-1}$ and were accompanied by SW and S winds, with $\mathrm{N}$ winds events in end of June, beginning of July, and end of August. From May to August, larval trajectories were mainly oriented southwards (Fig. 4, negative latitudinal distances in Fig. 5B and

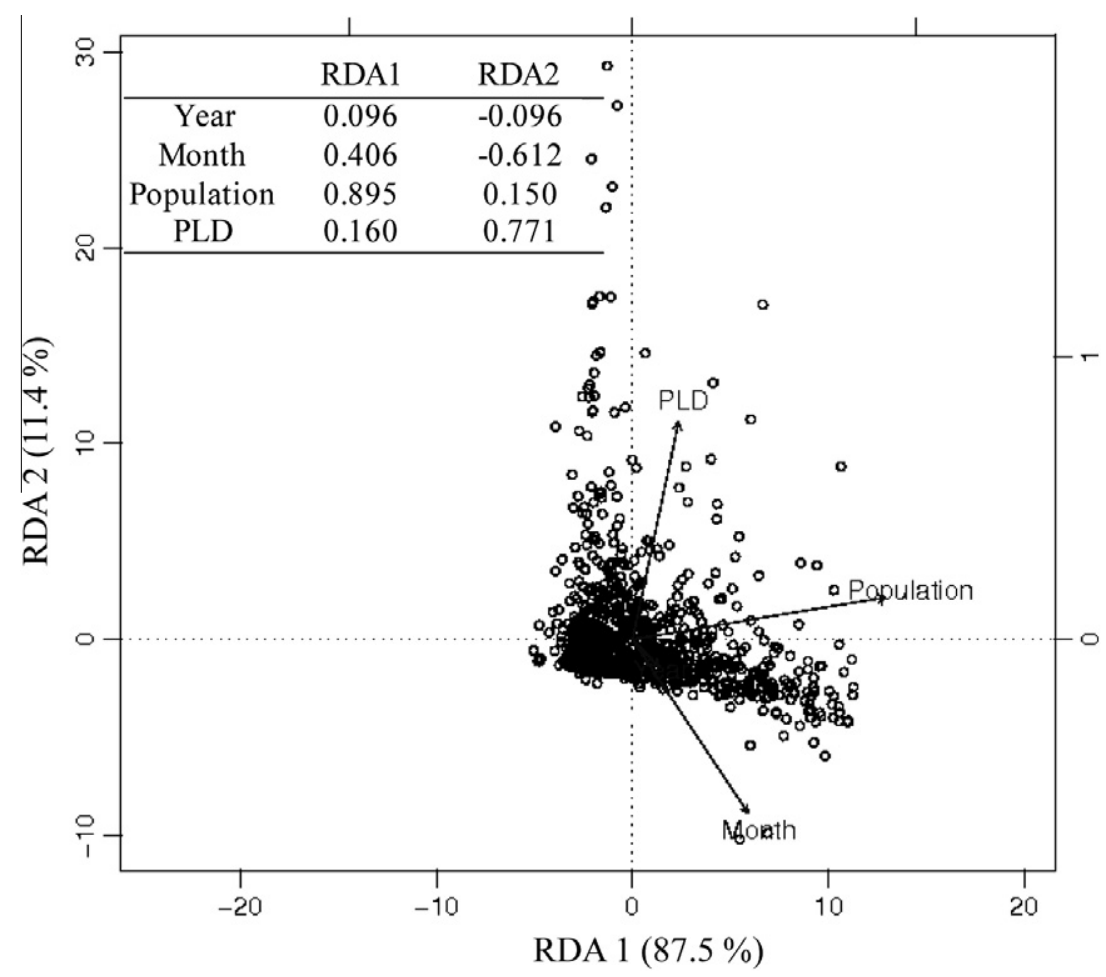

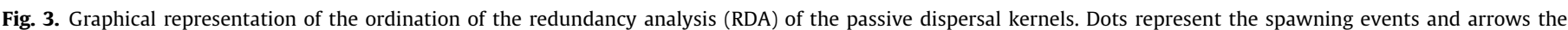

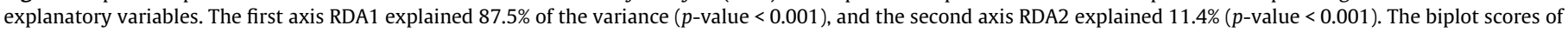
each constraining variable are indicated for both axes. 

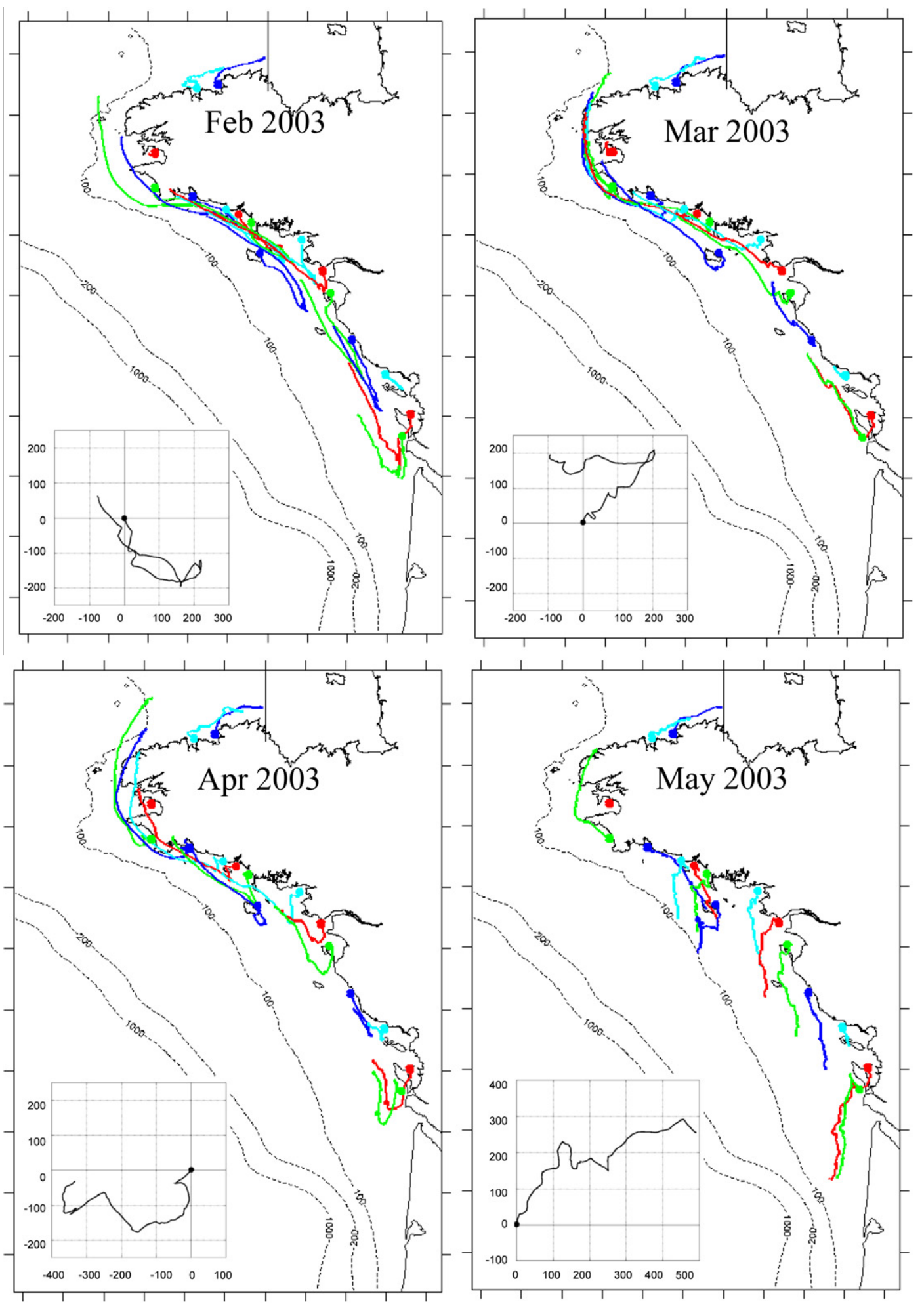

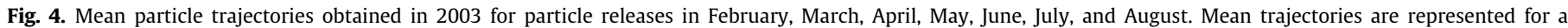

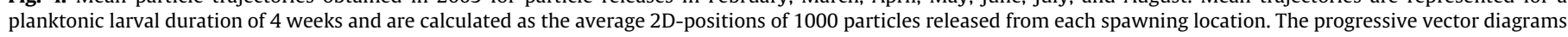
of wind conditions in Ushant during the dispersals are indicated, with black circles indicating the spawning day.

C), except for the particles released from Audierne population (spawning population \#4) for which transport was still northwestwards in May and June 2003 (Fig. 4). Among the spawning populations of the Bay of Biscay, dispersal patterns slightly differed depending on the coastline orientation. As an example, for the spawning populations \#15-16 (i.e. Antioche and Oléron), larval transport in February, March and April was first oriented southwards and then north-westwards. From South Brittany populations, transport occurred on shorter distances (mean orthodromic distance of $66 \pm 46 \mathrm{~km}, n=210$, PLD $=4$ weeks) than from Central Bay of Biscay populations (mean orthodromic distance of $83 \pm$ $59 \mathrm{~km}, n=245$, PLD $=4$ weeks). These differences were mainly 

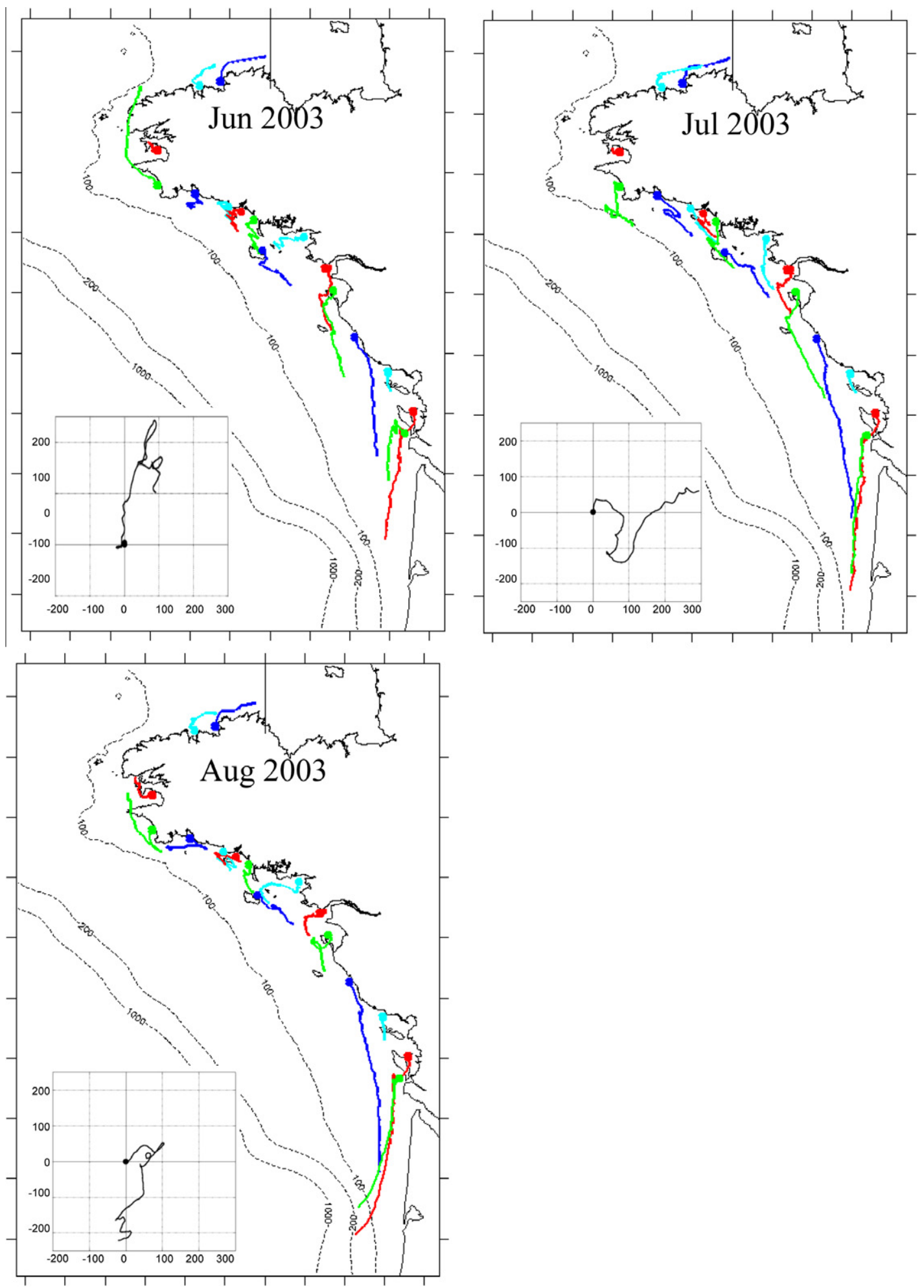

Fig. 4 (continued)

due to very short transport distances for South Brittany populations from May to August (mean orthodromic distances of $103 \mathrm{~km}$ in February-April vs. $19 \mathrm{~km}$ in May-August).

To illustrate the variability induced by the PLD in the dispersal patterns, six main descriptors of the dispersal kernels (i.e. mean dispersal distance and direction, major axis, minor axis, direction of the variance ellipse and sigma depth variance) obtained with a PLD of 2 and 4 weeks are given in Table 1 for three spawning dates and five spawning populations. The three spawning dates correspond to a release in early spring, in late spring and in summer (i.e. March, May, July 2003). The five spawning populations are representative of the different spawning areas: North Brittany (\#2: Morlaix), South Brittany (\#4: Audierne, \#7: Lorient), and Central Bay of Biscay (\#11: Loire, \#16: Oléron). In general, shorter PLD did not alter the dispersal direction but induced shorter dispersal distance and reduced dispersal variability (Table 1 ). Indeed, 
A

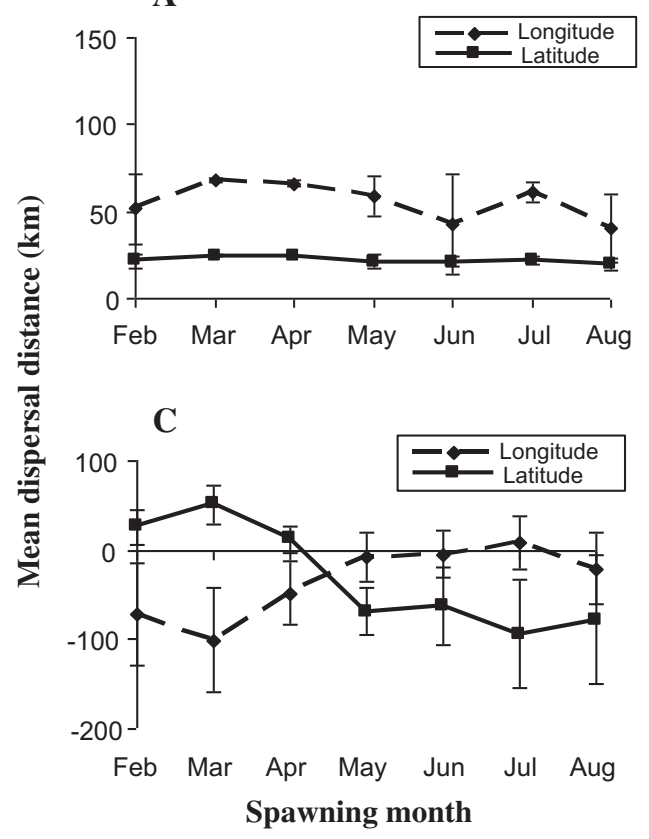

B

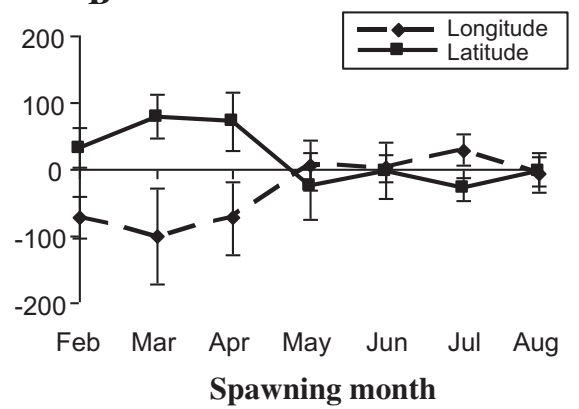

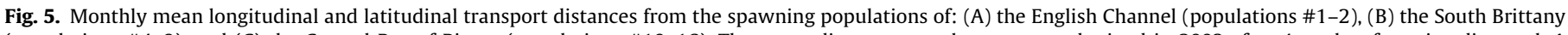

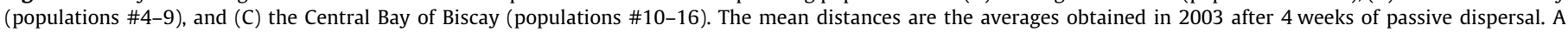
positive longitudinal distance indicates northwards transport. A positive latitudinal distance indicates eastwards transport.

Table 1

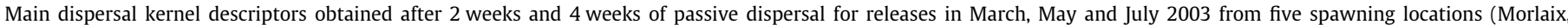

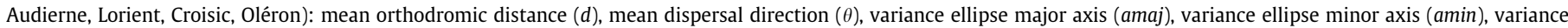
ellipse direction $\left(\theta_{m}\right)$, and variance in mean sigma depth $\left(s_{\sigma}\right)$. See text for the mathematical definitions of the dispersal kernel descriptors.

\begin{tabular}{|c|c|c|c|c|c|c|c|c|c|c|c|c|c|}
\hline \multirow[t]{3}{*}{ Month } & \multirow[t]{3}{*}{ Spawning } & \multicolumn{12}{|c|}{ Main dispersal kernels descriptors } \\
\hline & & \multicolumn{2}{|l|}{$d$} & \multicolumn{2}{|l|}{$\theta$} & \multicolumn{2}{|l|}{ amaj } & \multicolumn{2}{|l|}{ amin } & \multicolumn{2}{|l|}{$\theta_{m}$} & \multicolumn{2}{|l|}{$s_{\sigma}$} \\
\hline & & 2 weeks & 4 weeks & 2 weeks & 4 weeks & 2 weeks & 4 weeks & 2 weeks & 4 weeks & 2 weeks & 4 weeks & 2 weeks & 4 weeks \\
\hline \multirow{5}{*}{ March } & Morlaix & 45 & 74 & 22 & 20 & 37 & 36 & 5 & 9 & 13 & 12 & 0.08 & 0.08 \\
\hline & Audierne & 35 & 105 & -31 & -89 & 30 & 37 & 11 & 24 & -49 & 42 & 0.08 & 0.08 \\
\hline & Lorient & 67 & 178 & -6 & -31 & 25 & 37 & 6 & 29 & -2 & 78 & 0.09 & 0.09 \\
\hline & Loire & 45 & 155 & -22 & -20 & 42 & 81 & 8 & 9 & -24 & -19 & 0.09 & 0.09 \\
\hline & Oléron & 51 & 108 & -50 & -45 & 22 & 33 & 7 & 8 & -30 & -35 & 0.08 & 0.08 \\
\hline \multirow[t]{5}{*}{ May } & Morlaix & 20 & 54 & 24 & 20 & 30 & 46 & 5 & 5 & 13 & 13 & 0.08 & 0.08 \\
\hline & Audierne & 59 & 83 & -40 & -77 & 24 & 48 & 19 & 29 & -80 & 81 & 0.09 & 0.09 \\
\hline & Lorient & 18 & 62 & 126 & 124 & 12 & 30 & 6 & 18 & -7 & 19 & 0.07 & 0.07 \\
\hline & Loire & 32 & 69 & -137 & -106 & 33 & 52 & 16 & 32 & -2 & 4 & 0.05 & 0.05 \\
\hline & Oléron & 30 & 86 & -131 & -112 & 18 & 43 & 12 & 23 & 60 & 79 & 0.03 & 0.03 \\
\hline \multirow[t]{5}{*}{ July } & Morlaix & 13 & 60 & -77 & 19 & 16 & 41 & 8 & 6 & 3 & 12 & 0.09 & 0.09 \\
\hline & Audierne & 25 & 39 & -123 & 119 & 16 & 56 & 7 & 17 & -58 & -54 & 0.04 & 0.04 \\
\hline & Lorient & 8 & 29 & -116 & 128 & 15 & 28 & 5 & 11 & -13 & -33 & 0.09 & 0.09 \\
\hline & Loire & 17 & 40 & -129 & 97 & 25 & 50 & 11 & 11 & -43 & -53 & 0.07 & 0.07 \\
\hline & Oléron & 26 & 129 & -110 & -100 & 32 & 92 & 9 & 15 & 90 & 80 & 0.06 & 0.06 \\
\hline \multicolumn{2}{|c|}{ 35-date 16-population averages } & 40 & 73 & & & 21 & 39 & 8 & 15 & & & 0.07 & 0.07 \\
\hline
\end{tabular}

smaller axes of the ellipses of variance indicated denser clouds of particles. After 2 weeks of dispersal, mean dispersal distance reached $40 \pm 29 \mathrm{~km}(n=560)$, whereas it was almost doubled after 4 weeks of dispersal, reaching $73 \pm 51 \mathrm{~km}(n=560)$. The orientation $\theta_{m}$ of the ellipse and the variance of the sigma depth of the particles $s_{\sigma}$ were independent with the PLD.

\subsection{Role of larval behaviour on the dispersal patterns}

To assess the relative role played by larval behaviour in dispersal, three larval vertical distributions commonly reported in marine invertebrates were tested. For passive dispersal, mean sigma depth $\sigma_{m}$ of the particles varied with spawning populations and time since spawning (Fig. 6A). After one day of dispersal, mean sigma depth reached 0.5 , i.e. the centre of the water column. As expected, the mean sigma depth of the passive particles released from the English Channel population remained close to 0.5 during all the dispersal patterns (see population \#2 - Morlaix in Fig. 6A), indicating that passive particles were evenly distributed over the vertically-homogeneous water column of the English Channel. On the contrary, quick increases in mean sigma depths of passive particles from other spawning populations were observed. Indeed, since larval release occurred in coastal waters, passive particles were likely to encounter low salinity waters, especially in the 

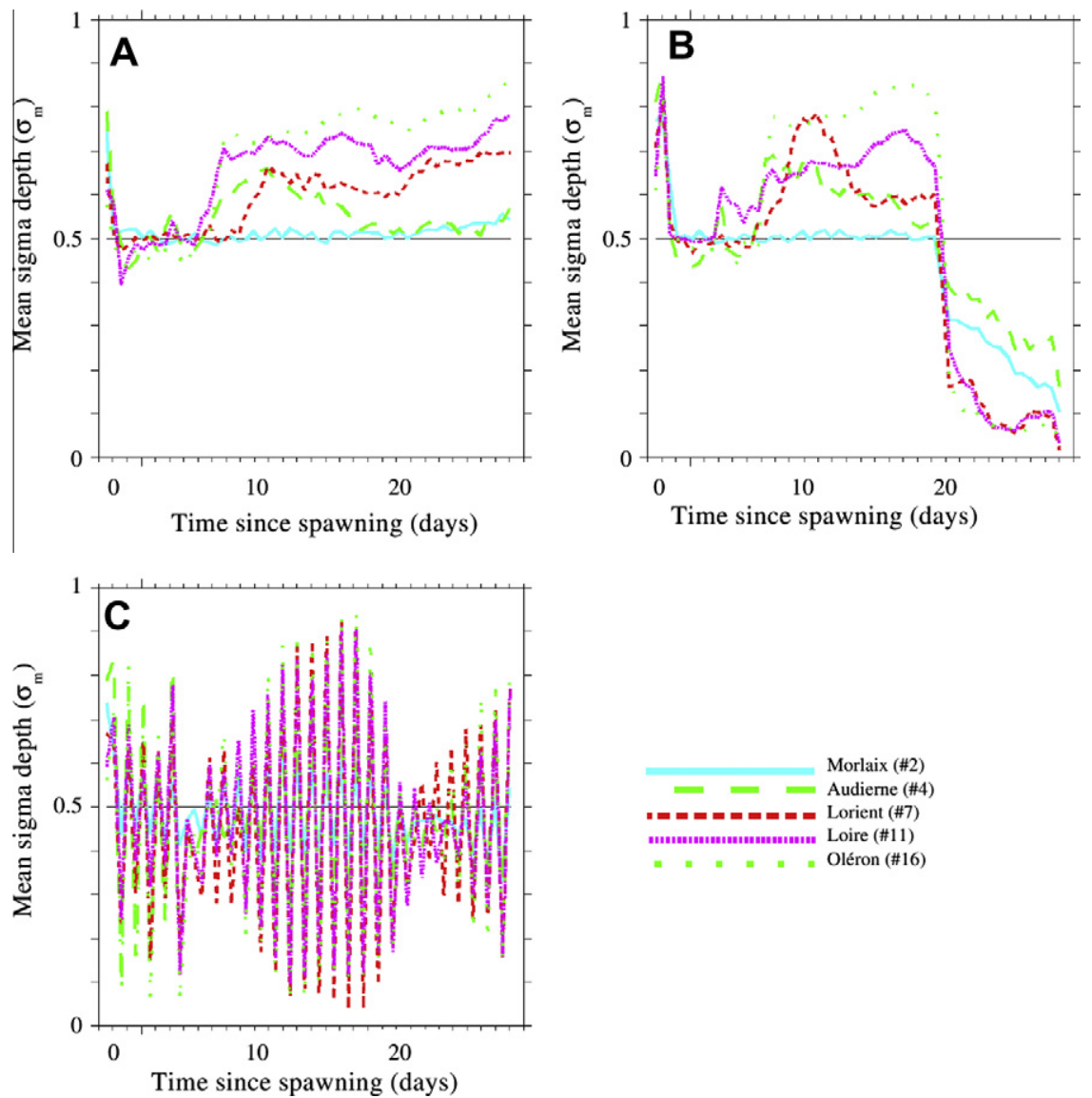

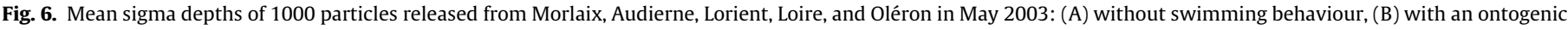
vertical migration, and $(\mathrm{C})$ with a diel vertical migration. The sigma depth is equal to zero at the bottom and to one at the surface.

vicinity of estuaries. Passive particles would then be trapped within the upper-layer lower-density plume waters when transported offshore, i.e. at constant mean vertical depth but with increasing water column height, resulting in an increase in the mean sigma depth. Large increases in sigma depth could also be linked to coastal upwelling events. Mean vertical position of larvae could also change with spawning month in relation to the relative position of the river plumes at spawning (data not shown).

As expected, vertical swimming behaviours modified mean sigma depths (Fig. 6B and C). With an ontogenic migration, vertical depth patterns observed at the beginning of the dispersal were close to those observed with no behaviour because of null vertical swimming speed (Fig. 6B). Then, after 20 days, particles moved with a negative swimming velocity so that they were mainly located close to the bottom at the end of the dispersal phase (Fig. 6B). A diel vertical migration imposed bi-daily variation of the mean vertical positions of the particles (Fig. 6C). Variations in the amplitude of the mean depth $\sigma_{m}$ were related to the variations of the vertical eddy diffusivity following the spring/neap tide cycles.

The redundancy analysis conducted on the dispersal kernels descriptors of the second set of simulations ( 7 months, 16 populations, three behaviours, one PLD, 1 year) used three explanatory variables: spawning month, spawning population, and larval behaviour which significantly alter larval dispersal (global $R^{2}=0.3090 ; p<0.005$ ) (Fig. 7). This analysis showed two significant canonical axes: the first axis RDA1 explained the major part of the variance $(94.3 \%, p<0.001)$ and was scored by larval behaviour and the spawning month, whereas the second axis RDA2 explained only a small part of the variance $(4.0 \%, p<0.001)$ and was scored by the spawning population and the spawning month.
This analysis confirmed the role of the spawning month and the spawning population location in the variability of the dispersal kernels and indicated that the particle vertical behaviour also significantly contributed to dispersal variability.

The values of the main dispersal kernel descriptors obtained with ontogenic and diel vertical migrations are given in Table 2 for five representative spawning populations. One-way ANOVAs conducted on each of the 17 dispersal kernel descriptors calculated for all populations indicated a significant effect $(p<0.05)$ of the swimming behaviour on the mean dispersal distance $(d)$. Tukey HSD a posteriori tests showed that mean dispersal distance $(d)$ varied only between the passive dispersal and the dispersal with an ontogenic migration $(p<0.05)$. ANOVA results also indicated that vertical swimming behaviour had a significant effect $(p<0.001)$ on the mean sigma depth $\left(\sigma_{m}\right)$ and on the variances of the 3-D positions, including the variance ellipse axes $\left(s_{x}, s_{y}, s_{d x}, s_{d y}, s_{\sigma}\right.$, amaj, amin). Tukey HSD a posteriori tests showed that mean sigma depth $\left(\sigma_{m}\right)$ and variance ellipse minor axis (amin) varied between each pair of behaviour types $(p<0.05)$, whereas variance ellipse major axis (amaj) differed between the dispersal with a diel vertical migration and the two other types of vertical distributions $(p<0.05)$.

More specifically, the mean dispersal and the variance ellipse axes obtained with vertical migrations were lower than those obtained with passive dispersal (Tables 1 and 2; Fig. 8), indicating denser clouds of particles. Mean dispersal distance reached $74 \mathrm{~km}$ with no vertical behaviour, $59 \mathrm{~km}$ with an ontogenic migration, and $63 \mathrm{~km}$ with a diel migration. For example in May 2003, although vertical behaviour did not significantly affect the mean particle trajectories, it decreased the spatial extension of particle 


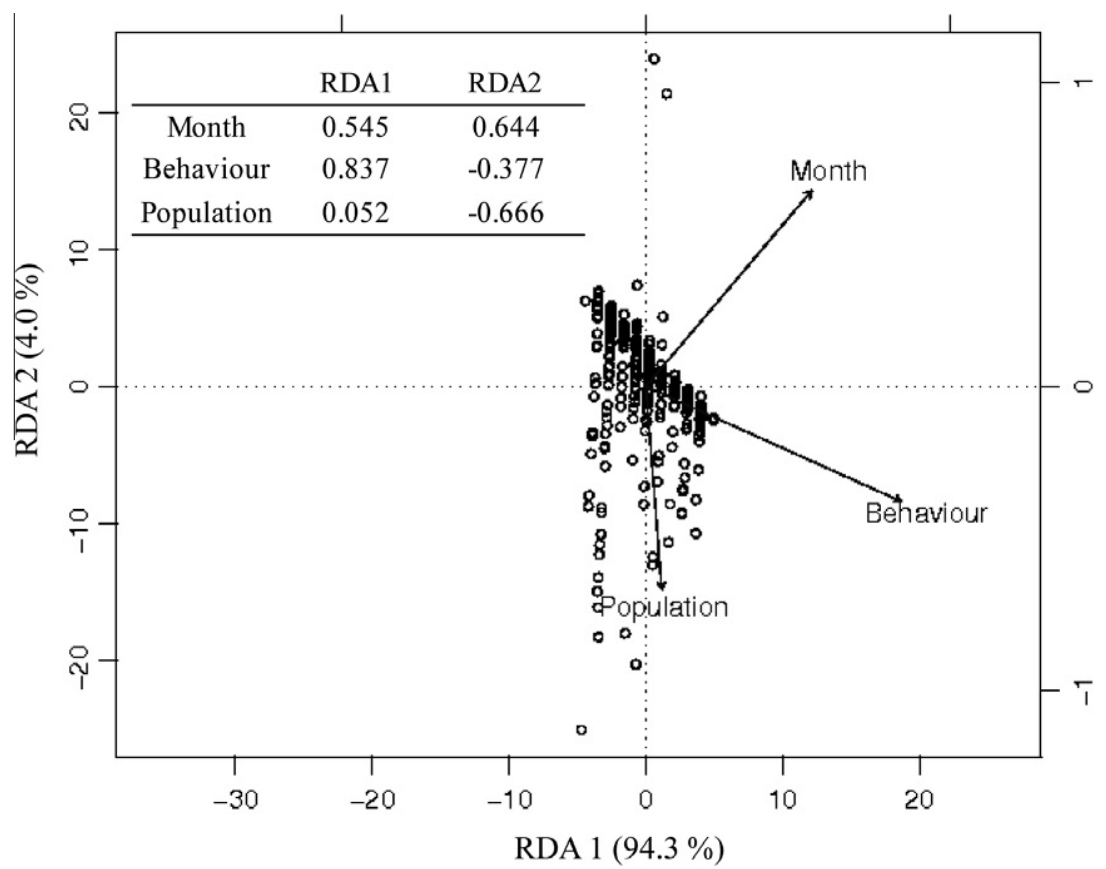

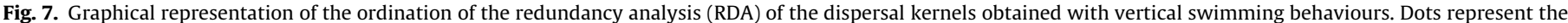

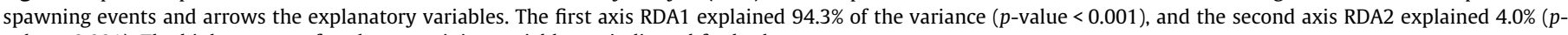
value $<0.001$ ). The biplot scores of each constraining variable are indicated for both axes.

clouds, such as for the particles released from spawning populations of Lorient (\#7), Loire (\#11) and Oléron (\#16) (Fig. 8). On

Table 2

Main dispersal kernel descriptors obtained after 4 weeks of dispersal with ontogenic and diel migrations and for releases in March, May and July 2003 from 5 spawning locations (Morlaix, Audierne, Lorient, Croisic, Oléron). See Table 1 for the definitions of the dispersal kernel descriptors.

\begin{tabular}{|c|c|c|c|c|c|c|c|}
\hline Month & Spawning & $d$ & $\theta$ & amaj & amin & $\theta_{m}$ & $s_{\sigma}$ \\
\hline \multicolumn{8}{|c|}{ (A) Ontogenic migration (year: 2003, PLD: 4 weeks) } \\
\hline \multirow[t]{5}{*}{ March } & Morlaix & 68 & 20 & 39 & 7 & 14 & 0.07 \\
\hline & Audierne & 94 & -84 & 38 & 26 & 45 & 0.05 \\
\hline & Lorient & 156 & -20 & 41 & 25 & -54 & 0.04 \\
\hline & Loire & 161 & -20 & 79 & 9 & -18 & 0.09 \\
\hline & Oléron & 108 & -45 & 33 & 8 & -36 & 0.08 \\
\hline \multirow[t]{5}{*}{ May } & Morlaix & 67 & 19 & 44 & 4 & 12 & 0.06 \\
\hline & Audierne & 72 & -69 & 45 & 26 & -86 & 0.05 \\
\hline & Lorient & 62 & -214 & 18 & 10 & -26 & 0.02 \\
\hline & Loire & 54 & -268 & 44 & 21 & -4 & 0.01 \\
\hline & Oléron & 67 & -106 & 27 & 17 & 44 & 0.01 \\
\hline \multirow[t]{5}{*}{ July } & Morlaix & 58 & 21 & 41 & 6 & 10 & 0.06 \\
\hline & Audierne & 12 & -122 & 47 & 17 & -46 & 0.04 \\
\hline & Lorient & 35 & -214 & 23 & 8 & -31 & 0.05 \\
\hline & Loire & 49 & -255 & 31 & 9 & -59 & 0.04 \\
\hline & Oléron & 31 & -265 & 32 & 9 & -82 & 0.04 \\
\hline \multicolumn{8}{|c|}{ (B) Diel migration (year: 2003, PLD: 4 weeks) } \\
\hline \multirow[t]{5}{*}{ March } & Morlaix & 77 & 21 & 33 & 10 & 7 & 0.06 \\
\hline & Audierne & 102 & -84 & 32 & 22 & 24 & 0.08 \\
\hline & Lorient & 102 & -84 & 32 & 22 & 24 & 0.08 \\
\hline & Loire & 131 & -19 & 47 & 7 & -19 & 0.05 \\
\hline & Oléron & 94 & -47 & 35 & 5 & -29 & 0.05 \\
\hline \multirow[t]{5}{*}{ May } & Morlaix & 58 & 19 & 46 & 5 & 12 & 0.04 \\
\hline & Audierne & 57 & -71 & 54 & 25 & -76 & 0.06 \\
\hline & Lorient & 58 & -213 & 11 & 6 & -42 & 0.03 \\
\hline & Loire & 65 & -251 & 31 & 9 & -56 & 0.02 \\
\hline & Oléron & 50 & -269 & 25 & 9 & -81 & 0.02 \\
\hline \multirow[t]{5}{*}{ July } & Morlaix & 58 & 21 & 41 & 6 & 10 & 0.06 \\
\hline & Audierne & 15 & -211 & 28 & 9 & -23 & 0.06 \\
\hline & Lorient & 10 & -262 & 6 & 3 & -12 & 0.02 \\
\hline & Loire & 30 & -269 & 55 & 6 & -49 & 0.03 \\
\hline & Oléron & 14 & -98 & 38 & 9 & -86 & 0.05 \\
\hline
\end{tabular}

the other hand, with a diel vertical migration, larval particles released from the Bay of Biscay populations remained closer to the shore (Fig. 8C).

\subsection{Connectivity patterns}

For each spawning date, connectivity matrices and exchange rates were calculated, distinguishing northwards exchanges, southwards exchanges, and self-retention. Fig. 9A represents the monthly-averaged connectivity matrices obtained after 4 weeks of passive dispersal. Whatever the month, higher exchange rates were observed between neighbouring populations, usually with maximum exchange rates along the matrix diagonal, i.e. corresponding to self-retention. Whatever the spawning date, the average percentage of self-retention was roughly constant, with a mean value of $8.19 \pm 1.93 \%(n=35$, PLD $=4$ weeks $)$. Between spawning populations, highest self-retention rates were observed for populations \#3 (Douarnenez, 61.83\%) and \#14 (Ile de Ré, 27.70\%). From February to April, northwards exchanges were higher than southwards exchanges $(6.10 \pm 4.73 \%$ and $2.48 \pm 2.03 \%$, respectively, $n=15, P L D=4$ weeks). In contrast, northwards exchanges were lower than southwards exchanges $(1.35 \pm 1.21 \%$ and $4.49 \pm 1.36 \%$, respectively, $n=20$, PLD $=4$ weeks) from May to August.

As suggested by the analysis of the dispersal patterns (see Section 3.1), connectivity patterns from the three most northern populations did not vary with the spawning month. Particles from North Brittany populations (\#1-2) never supplied the southern populations and the Douarnenez population (\#3) was relatively isolated from the other populations, with high self-retention rates (61.83 $\pm 16.49 \%, n=35, \mathrm{PLD}=4$ weeks).

Seasonal variations of connectivity were observed for the populations of the Bay of Biscay. From February to April, exchanges occurred preferentially northwards. Highest northwards exchanges occurred in March, in particular from the Central Bay of Biscay populations to the South Brittany populations with a mean value of $10.67 \pm 2.70 \%$, whereas southwards exchanges reached only $1.05 \pm 1.17 \%(n=5$, PLD $=4$ weeks $)$. Southwards exchanges were also observed in February and April, indicating bidirectional 

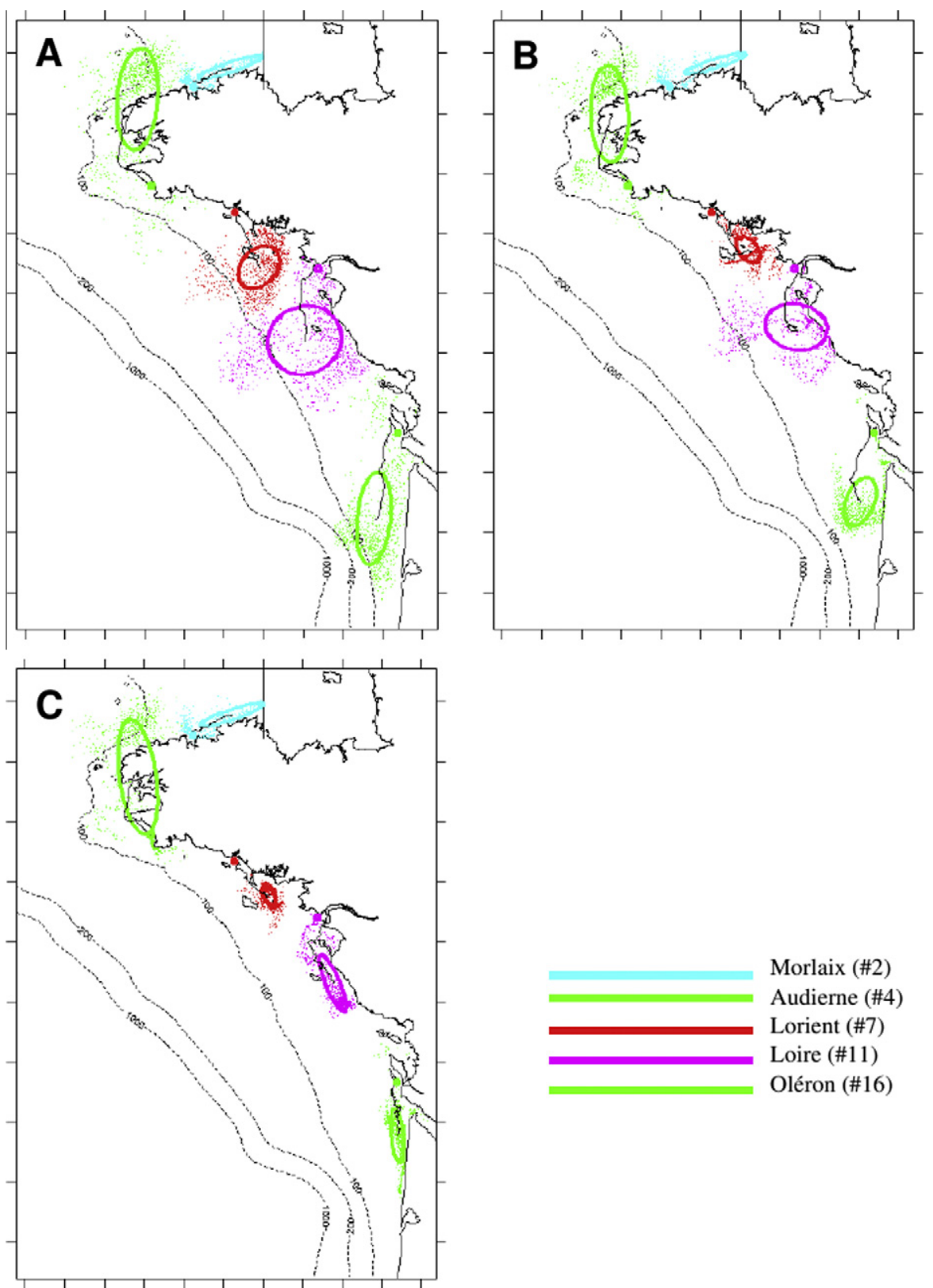

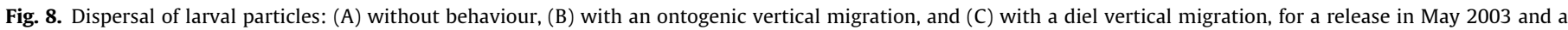

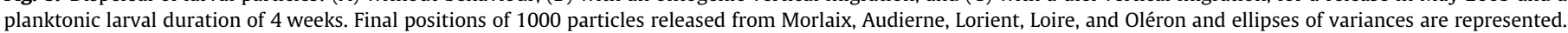
The five spawning locations are indicated by a dot. The main descriptors of these dispersal kernels are presented in Tables 1 and 2 .

exchanges between the South Brittany and the Central Bay of Biscay populations (northwards and southwards exchange rates of $4.99 \pm 4.77 \%$ and $3.98 \pm 2.58 \%$ in February and of $2.63 \pm 2.37 \%$ and $2.40 \pm 0.99 \%$ in April, $n=5$, PLD $=4$ weeks). From May to August, exchanges occurred preferentially southwards, but only between relatively close populations, indicating that the particles transported southwards during those months were not able to encounter suitable settlement areas in coastal zones.

As expected, shorter PLD induced higher self-retention rates and higher exchange rates between neighbouring populations (Fig. 9B). Larval exchanges were 1.82 times higher for a PLD of 2 weeks than 4 weeks. Conversely, exchanges from the Central Bay of Biscay populations to the South Brittany populations were favoured with longer PLD. More specifically, populations \#10 (Vilaine) to \#13 (Saint-Gilles) were able to supply populations \#4 (Audierne) to \#12 (Bourgneuf) for a PLD of 4 weeks. On the con- trary, exchanges from populations \#13 (Saint-Gilles) to populations further north than population \#10 (Vilaine) were never observed for a PLD of 2 weeks.

One-way ANOVAs on the connectivity size from the 70 connectivity matrices obtained without behaviour (two PLD, 5 years, 7 months) confirmed that spawning year had no influence on connectivity, contrary to PLD and spawning month (Table 3A). Connectivity size decreased with the PLD and the spawning month (Fig. 10). Tukey HSD a posteriori tests showed a significantly different connectivity size between February and July or August spawnings $(p<0.05)$. For a PLD of 2 weeks, mean connectivity size varied from 24 to 60 connections, with a mean of $37 \pm 8$ connections, whereas it varied from 32 to 89 connections, with a mean of $55 \pm 13$ connections, for a PLD of 4 weeks. For a 4-week PLD, mean connectivity size reached $65 \pm 12$ connections from February to April, then only $48 \pm 9$ connections from May to August. 
A

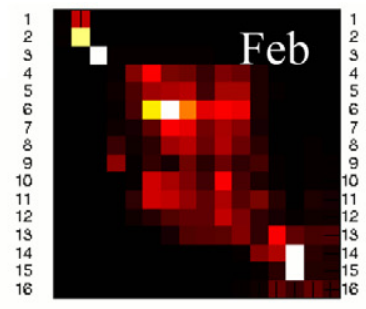

12345678910111213141516

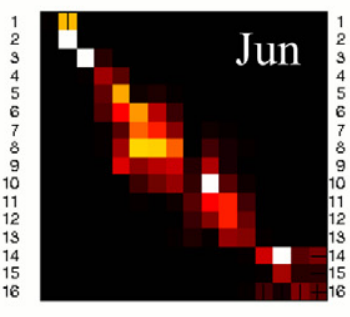

12345678910111213141516

B

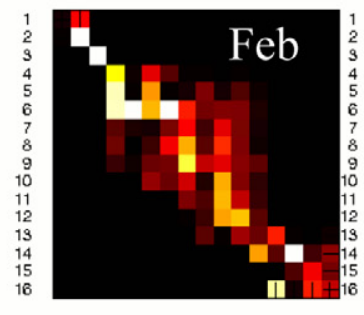

12945678910111213141516

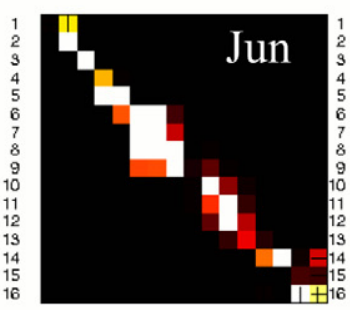

12345678910111213141516

C

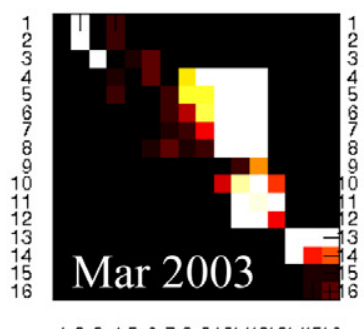

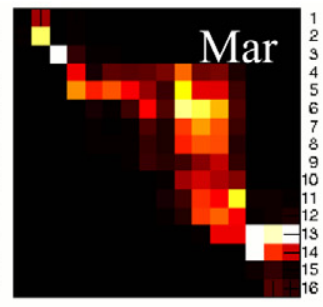

12345678910111213141516

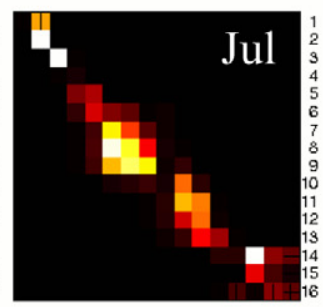

12345678910111213141516

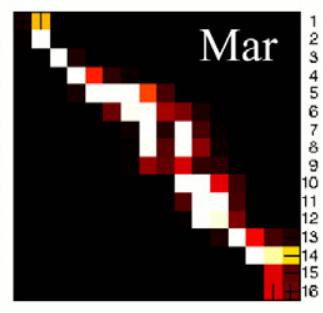

12345678910111213141516

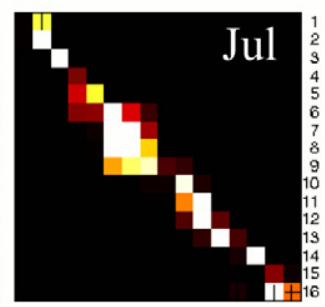

12345678910111213141516

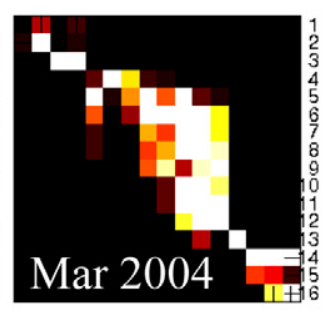

12345678910111213141516

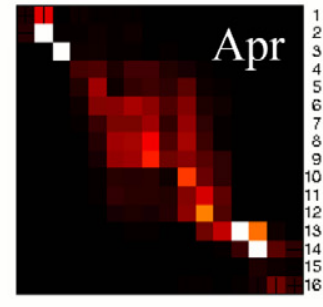

12345678910111213141516

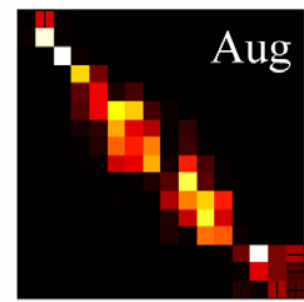

12345678910111213141516

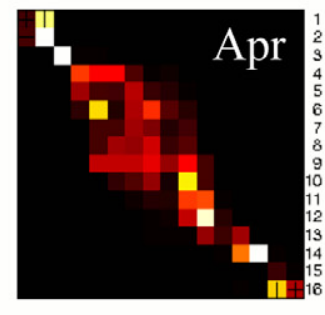

12345678910111213141516

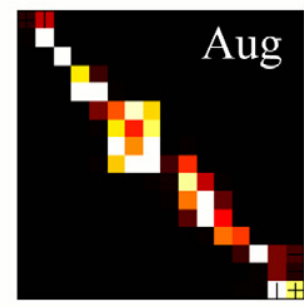

12345678910111218141518

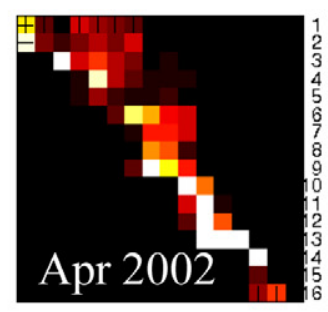

12345678910111213141516

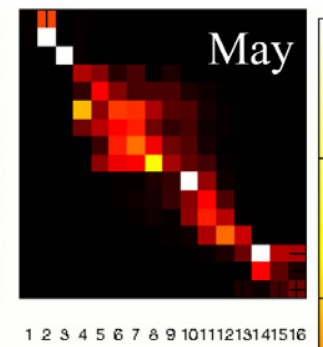

100

60

40

20

0

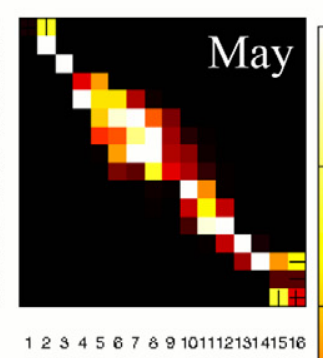

100

80

40

20

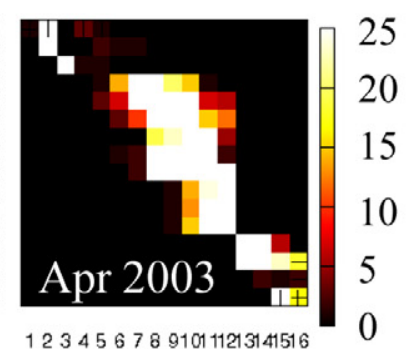

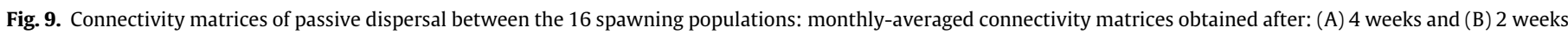

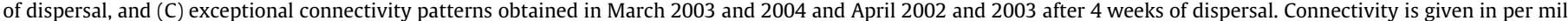

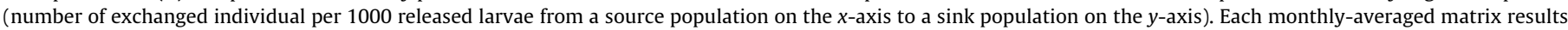

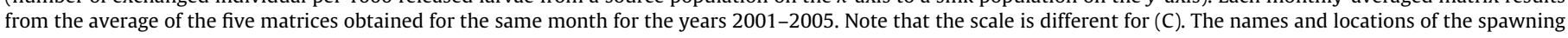
populations are indicated in Fig. 1B.

The 7-month averaged connectivity matrices obtained in 2003 for three simple larval behaviours and a PLD of 4 weeks are presented in Fig. 11. A diel vertical migration did not significantly alter the mean connectivity matrix obtained in 2003 in comparison with passive larvae. On the other hand, self-retention was strongly increased by an ontogenic migration and reached $10 \%$, whereas it reached only $7 \%$ for passive particles and a diel migration. Consequently, the transport success was higher with an ontogenic migration (21\%) than without behaviour or with a diel migration (17\%).

Within the second set of simulations, connectivity size varied significantly with the spawning month and the larval behaviour 
Table 3

Results of the ANOVA on the connectivity sizes. One-way ANOVA on passive connectivity (A) relies on 2 values of planktonic larval duration (PLD), five spawning years, and seven spawning months (passive dispersal). Two-way ANOVA with larval behaviour (B) relies on three behaviour types (no behaviour, ontogenic migration, diel migration) and seven spawning months (one PLD $=4$ weeks, 1 year $=2003$ ). The significance of each test is indicated.

\begin{tabular}{|c|c|c|c|c|c|}
\hline & Df & Sum Sq & Mean Sq & $F$ value & $\operatorname{Pr}(>F)$ \\
\hline \multicolumn{6}{|c|}{ (A) Passive (one-way ANOVA) } \\
\hline PLD & 1 & 5906.4 & 5906.4 & 48.822 & $1.495 \mathrm{E}-009^{* * *}$ \\
\hline Residuals & 68 & 8226.5 & 121 & & \\
\hline Year & 4 & 1339.8 & 334.9 & 1.7018 & 0.1603 \\
\hline Residuals & 65 & 12793.1 & 196.8 & & \\
\hline Month & 6 & 3533 & 588.8 & 3.4997 & $0.004743^{* *}$ \\
\hline Residuals & 63 & 10599.9 & 168.3 & & \\
\hline \multicolumn{6}{|c|}{ (B) With behaviour (two-way ANOVA) } \\
\hline Behaviour & 2 & 1492.3 & 746.1 & 28.42 & $2.81 \mathrm{E}-005^{* * *}$ \\
\hline Month & 6 & 4895.8 & 816 & 31.08 & $1.23 \mathrm{E}-006^{* * *}$ \\
\hline Residuals & 12 & 315 & 26.3 & & \\
\hline
\end{tabular}

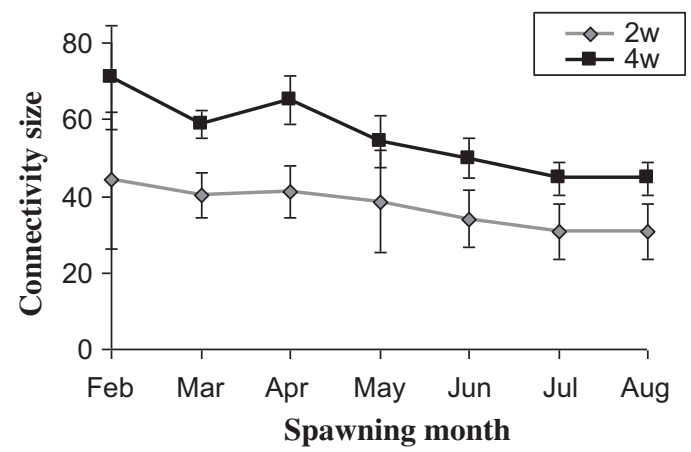

Fig. 10. Mean connectivity sizes obtained for each spawning month and for a PLD of 2 weeks (in black) or 4 weeks (in gray). The mean connectivity sizes are calculated for the years 2001-2005 from the 7 monthly-mean connectivity matrices obtained for each PLD value without behaviour.

$(p<0.001)$ (Table 3B, Fig. 12). Whatever the larval behaviour, connectivity size decreased from February to May 2003, then was constant from May to August 2003 (Fig. 12). Without behaviour, the mean connectivity size reached $58 \pm 19$ connections, with a maximal value of 89 connections in February and a minimum value of 39 connections in May. Mean connectivity size was lower with an ontogenic migration $(55 \pm 19$ connections, $\max =90$ in February, $\min =40$ in July) and much lower with a diel migration ( $39 \pm 12$ connections, $\max =61$ in February, $\min =27$ in May). To conclude, an ontogenic migration increased the self-retention and hence the total transport success whereas a diel migration did not modify the mean transport success but decreased the connectivity size.

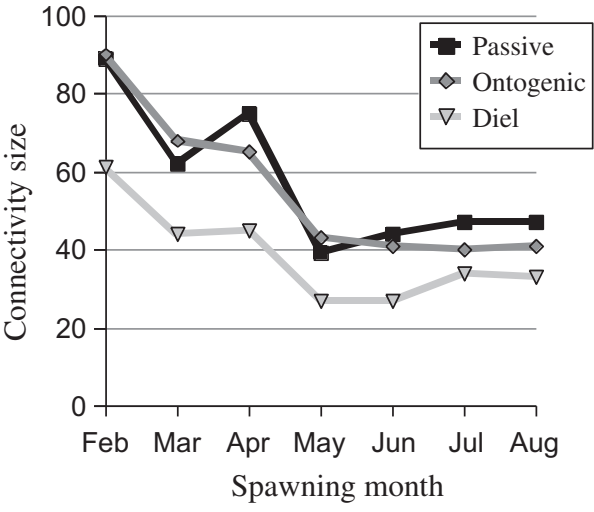

Fig. 12. Consequences of larval behaviour on the connectivity sizes in relation to spawning month. Results were obtained in 2003 after 4 weeks of dispersal.

For passive dispersal, connectivity from the South Brittany populations to the English Channel population was observed for only five spawning dates among 35 (i.e. March 2003 and 2004, April 2002 and 2003, and May 2001), and only for a PLD of 4 weeks. When existing, larval exchanges from the Bay of Biscay to the English Channel populations were very low, from $0.1 \%$ (the minimal value for 1000 particles released) to $0.7 \%$. The connectivity matrices obtained for four of those five spawning dates are presented in Figure 9C. In March 2003 and 2004, and in May 2001, only a total of 3-4 particles from Audierne (population \#4) reached the English Channel populations (populations \#1-2) while a high connectivity existed from the Central Bay of Biscay populations to the South Brittany populations. In April 2003, a total of eight particles from populations \#4-7 (Audierne, Concarneau, Pouldu, Lorient) reached the English Channel populations (\#1-2). High connectivity between the Central Biscay and South Brittany was also observed. In April 2002, a total of 40 particles from populations \#4-7 (Audierne, Concarneau, Pouldu, Lorient) reached the English Channel populations. All those exceptional connectivity patterns resulted from extremely strong northwards followed by eastwards larval transport. In particular for the year 2002, S-SE winds in March favoured the density-driven northward transport of plume waters, and were followed by SW winds in April, favouring intrusion of plume waters into the English Channel.

In March and April 2003, connectivity from the Bay of Biscay to the western English Channel was also observed when vertical larval behaviour was considered (ontogenic and diel migrations). With a diel vertical migration, only two particles from South Brittany were able to settle in the western Channel in March and April instead of 3 and 8 with no behaviour. An ontogenic migration permitted a larger number of larval particles from South Brittany to successfully settle in the English Channel populations, with a total of nine particles in March 2003 (mainly from Audierne, population
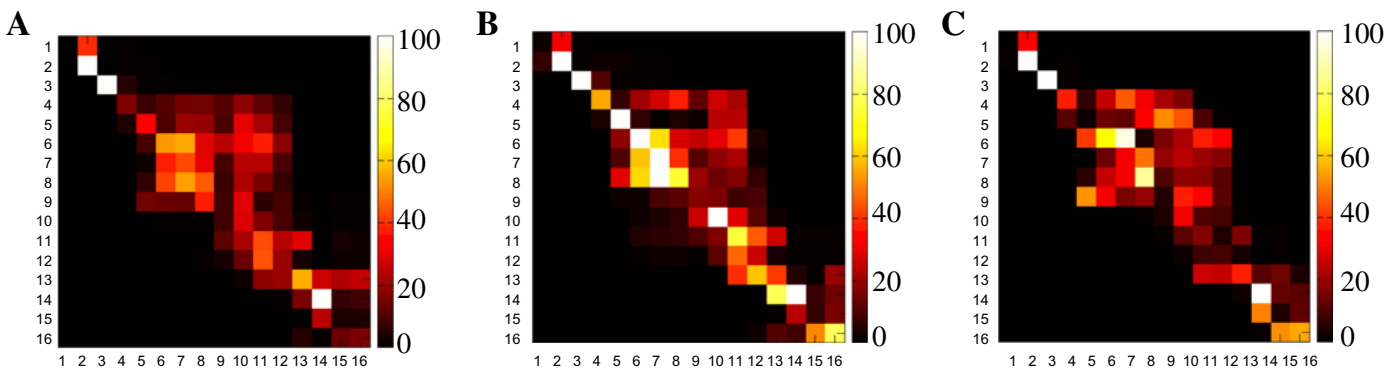

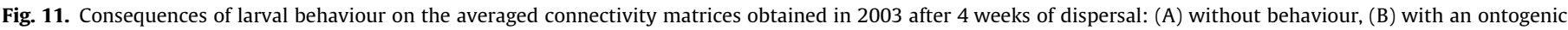
migration, and $(C)$ with a diel migration. 
\#4) and of 25 particles in April 2003 (mainly from Concarneau, population $\# 5$, with a connectivity of $1 \%$ to Morlaix, population \#2). A higher connectivity between South Brittany and English Channel was then observed in April 2003 for a PLD of 4 weeks and with an ontogenic migration than without behaviour.

\section{Discussion}

A generic bio-physical model of invertebrate larval dispersal was developed in the Bay of Biscay and the western English Channel in order to assess the relative role of hydrodynamics and simple biological traits (i.e. monthly spawning dates, constant PLD, simple larval vertical migrations) on larval dispersal in the North-East Atlantic, and to investigate the connectivity of marine invertebrate populations between the main bays of the study area through a biogeographical transition zone. No temporal and spatial variation of the reproductive outputs was considered and no larval mortality was taken into account as the variability of this parameter remains poorly known for marine invertebrate larvae (Levin, 2006). The present work corresponds then to an 'order zero' connectivity study in the Bay of Biscay, such as previously done in the south-eastern US continental shelf (Edwards et al., 2007) or in the northern Gulf of California (Marinone et al., 2008), and focused mainly on the interactions between larval dispersal and hydrodynamics variability. On the other hand, the numerical model did not include explicit horizontal eddy diffusion although it can affect larval dispersal of marine organisms and decrease the connectivity of marine populations (Okubo, 1994; Cowen et al., 2000). Through a sensitivity analysis, Edwards et al. (2007) quantified the consequences of horizontal diffusivity on larval transport using three values of horizontal eddy diffusivity $\left(1,10\right.$ and $\left.50 \mathrm{~m}^{2} \mathrm{~s}^{-1}\right)$. They demonstrated that eddy diffusivity mainly increased the variance of dispersal, increasing the major and minor axis of the variance ellipse and that high eddy diffusivity $\left(50 \mathrm{~m}^{2} \mathrm{~s}^{-1}\right.$ ) also reduced mean dispersal distance because of increased variance. Because of the lack of horizontal diffusion in our model, we may have underestimated the variance of the dispersal but overestimated the mean dispersal. However, the comparison between the order of magnitude of the variance ellipse observed in our study with the one observed by Edwards et al. (2007) for an eddy diffusivity of $10 \mathrm{~m}^{2} \mathrm{~s}^{-1}$ suggests that our model is sufficiently diffusive. Our assumptions that most horizontal diffusion is related to vertical eddy diffusivity and that advective horizontal processes prevail over diffusion due to sub-grid-scale processes in the Bay of Biscay seem correct to a first approximation.

\subsection{Relative role of hydrodynamics and biological traits in larval transport}

In a first set of simulations, passive dispersal was simulated for 35 monthly spawning dates from February to August for the years 2001 to 2005, from 16 coastal populations located in the main bays and estuaries of the study area, and for two common values of PLD. Our results indicated that no significant inter-annual variability of the dispersal kernels was observed whereas strong variability of the dispersal kernels was due to spawning month, spawning population location, and PLD. In a second set of simulations, which considered common larval swimming behaviours, results underlined the importance of larval behaviour on dispersal and connectivity patterns.

\subsubsection{Spawning date, spawning population, and seasonality of the circulation}

The absence of year-to-year variations in dispersal patterns may be surprising as inter-annual variations of the hydrology of the Bay of Biscay have been reported by Planque et al. (2003) from the comparison of hydroclimatic data measured in the 1990s and multi-decadal historical records. Their analysis revealed that hydroclimatic factors, such as sea surface temperature, wind speed and river run-off, were highly variable at the temporal scale of several decades. This strong inter-annual hydroclimatic variability induces high inter-annual variability of hydrological structures, as shown by Puillat et al. (2004) from a synthesis of 9 years of hydrographic measurements in the bay during the 1990s. Hydrographic variability is caused by long-term variations in river run-off from the Loire and Gironde, responsible for the presence of low salinity waters, and in wind conditions, responsible for the transport of those low salinity waters (Puillat et al., 2004; Kelly-Gerreyn et al., 2006). The hydrographic variability on the French continental shelf of the Bay of Biscay results also from high seasonal and short-term meteorological variability. Indeed, the circulation in the Bay of Biscay is well known for its strong seasonal patterns due to the seasonal variations in river run-off and in wind speed and direction (SW winds from September to March, NW winds from March to September) (Koutsikopoulos and Le Cann, 1996; Puillat et al., 2004). Moreover, short-term meteorological variability plays an important role in hydrodynamic variability by inducing mesoscale structures, such as transient upwellings or fresh water lenses (Puillat et al., 2006; Kelly-Gerreyn et al., 2006).

In the present work, the MARS 3-D hydrodynamic model, was forced by realistic climatic forcing from recorded data of river run-offs and wind conditions in order to reproduce realistic hydrodynamic variability. In our simulations, larval dispersal was simulated monthly over 5 years with a PLD of 2 or 4 weeks, which means that the temporal scale of larval life (PLD) was equal to or shorter than the temporal scale of spawning (time interval between two consecutive spawning events). Hence, at the spatial and temporal scales of larval dispersal that were considered in our study, the year-to-year variations in dispersal kernels were negligible compared to the variations due to the spawning month (seasonal variations) and the spawning location (mesoscale variations). Depending on the spawning month and population, larval particles encountered different mesoscale structures, such as river plumes, that, combined with wind conditions, altered their transport by density-driven and wind-induced currents (Kelly-Gerreyn et al., 2006).

Mean transport direction differed from the three main spawning zones of the study area. In the English Channel, larval particles were transported northeastwards, whatever the spawning month, because of the strong northeastwards tidal residual circulation (Salomon and Breton, 1993). Although wind-induced currents can greatly affect larval transport over short-term periods of a few days, their influence is reduced over 2 or 4 weeks. In South Brittany and in the Central Bay of Biscay, seasonal shifts in transport direction were observed. In late-winter and early spring, north-westwards transport was observed because of the geostrophic north-westwards transport of plume waters along the Brittany coasts which is favoured by NE winds consistently with Ekman theory (Kelly-Gerreyn et al., 2006). In late spring and summer, transport from the Bay of Biscay populations occurred generally southwestwards to southeastwards, because of $\mathrm{W}$ to $\mathrm{N}$ winds, also known to favour cross-shore transport and transient upwellings in the area (Puillat et al., 2004, 2006).

Previous modelling has underlined the influence of the spawning date in larval transport suggesting that a favourable temporal window of spawning may exist to maximize the success of dispersal (Edwards et al., 2007; Ayata et al., 2009). Here, the simulated spawning dates extended from February to August, which corresponds to common spawning dates of benthic invertebrates in temperate zones (Olive, 1995). As mentioned above, dispersal kernels varied throughout the season with the spawning month. 
For a given species able to spawn from early spring to summer, connectivity patterns could be very complex and variable in relation with the hydrodynamic variability of the Bay of Biscay. The larvae of such species with an extended spawning period will likely undergo very different transport pathways depending on their release date, since early and late spawnings will induce different dispersal and connectivity patterns. For a given species, the larvae released in early spring from the Bay of Biscay populations would mainly be transported to the north and contribute to northward exchanges, whereas larvae released in late spring or early summer would preferentially be transported to the south and contribute to southwards exchanges. Since the larvae of a given species inhabiting fragmented habitat will have different fates depending on their spawning date, larvae released early or late in the spawning season will contribute differently to the metapopulation dynamics. Strong variability of larval transport and connectivity patterns could then represent an advantage for the sustainability of invertebrate subpopulations in fragmented habitats by increasing the likelihood of successful larval transport (Byers and Pringle, 2006). Metapopulation dynamics would then differ between early-spawning and late-spawning species and species phenology could be partly responsible for the species distribution.

\subsubsection{Planktonic larval duration, larval behaviour, and environment}

In the present study, simple common biological traits of the larval life were considered. Planktonic larval duration (PLD) was supposed to last 2 or 4 weeks, as commonly reported for many marine invertebrates (Kinlan and Gaines, 2003). PLD value played a significant role in the simulated dispersal kernels, mainly affecting the mean dispersal distances. As observed before, longer PLD increased the mean dispersal distances (Edwards et al., 2007; Marinone et al., 2008; Mitarai et al., 2008) but decreased connectivity (Treml et al., 2008). More specifically, a decrease of $50 \%$ of the PLD from 4 to 2 weeks induced: (1) a decrease of $44.62 \%$ of mean dispersal distance, (2) an increase in self-retention, (3) an increase of the connectivity (larval exchange rates) between neighbour populations, (4) a decrease of the connectivity between more distant populations, and (5) a decrease in the connectivity size (number of connections) of the metapopulation.

In the study area, temperature fields are highly variable in time and space, and should then induce large temporal and spatial variations of the PLD. For species able to spawn during all of the spring season, spawning date will affect larval development rate because of the temporal gradient of water temperature encountered during the spawning season (Reitzel et al., 2004). From published experimental laboratory studies on 72 marine taxa, O'Connor et al. (2007) proposed a general relationship between water temperature ( $T$ in ${ }^{\circ} \mathrm{C}$ ) and PLD (in days) as follows:

$\ln (P L D)=3.17-1.34 \ln \left(\frac{T}{T_{c}}\right)-0.28\left(\ln \left(\frac{T}{T_{c}}\right)\right)^{2}$

with $T_{C}=15^{\circ} \mathrm{C}$

From February to August, monthly-mean temperatures of coastal waters along the Bay of Biscay French coasts vary from $10^{\circ} \mathrm{C}$ to $19{ }^{\circ} \mathrm{C}$ (Gómez-Gesteira et al., 2008) so that PLD would decrease by 3 weeks (i.e. from 39 to 17 days) from the beginning to the end of the spawning period for a species with a PLD of 24 days at $15^{\circ} \mathrm{C}$. Hence larvae released in late spring or in summer could exhibit shorter PLD, because of warmer water temperature, than for the larvae released in early spring, when water temperature is colder. For larvae released in early spring in the Bay of Biscay, longer PLD would favour northwards transport along longer distances, hence northwards exchanges with distant populations. In contrast, for larvae released in late spring or in summer, shorter PLD would favour southwards transport along shorter distances, favouring southwards exchanges with neighbouring populations and selfretention. Variations of the PLD could also be induced by spatial variations in the temperature field. For a given spawning date, water temperatures encountered by the larvae can vary in space depending on the larval trajectory. In particular, temperature gradients in the Bay of Biscay occur horizontally between coastal and offshore waters and/or vertically between surface and bottom waters. For example, a surface water temperature gradient is commonly reported in summer and can reach $4{ }^{\circ} \mathrm{C}$ between coastal and offshore waters, with temperatures of 15 and $19{ }^{\circ} \mathrm{C}$ respectively (Lazure et al., 2009). From the equation proposed by O'Connor et al. (2007), such an increase in water temperature from 15 to $19{ }^{\circ} \mathrm{C}$ could decrease the PLD by one week, from 24 days to 17 days. PLD reduction due to temperature increases in time or space could then induce significantly shorter dispersal distance and lower long-distance connectivity.

The general relationship described by O'Connor et al. (2007) may however vary between species. Species-specific environment-dependent larval growth and development are frequently taken into account in individual-based models of fish larval dispersal (e.g. Allain et al., 2007) because growth parameters of fish larvae are relatively well known. On the contrary, individual-based models (IBM) of invertebrate larval dispersal taking into account larval growth are scarce (e.g. Pedersen et al., 2003) because of the lack of sufficient knowledge on invertebrate larval biology, especially for non-commercial species. Since temperature fields are calculated by the MARS-3D model, future modelling work in the context of climatic change will require considering individual PLD as a function of the temperatures encountered by the larval particle throughout its life time following laboratory experiments (O'Connor et al., 2007).

Three simple vertical larval distributions were considered in this study: no behaviour as a reference case, an ontogenic vertical migration, and a diel vertical migration. In our simulations, vertical distribution of passive larvae varied depending on the hydrodynamic conditions encountered by the larval particles. In the English Channel, where the water column is vertically homogeneous because of intense tidal mixing (Salomon and Breton, 1993), mean depth of passive particles corresponded to mean water column depth $\left(\sigma_{m}=0.5\right)$. On the contrary, in the vicinity of estuaries, where a strong vertical stratification existed, passive particles were mainly located in the top layers of the water column $\left(\sigma_{m}>0.5\right)$, i.e. trapped in the low salinity water plume. Thus, passive particles were not evenly distributed throughout the whole water column but remained mainly confined in a typical water mass (Shanks et al., 2002). Furthermore, invertebrate larvae do not always behave passively and vertical swimming behaviour may affect larval dispersal according to the vertical shear stress (Garland et al., 2002). In stratified environments, such as the Bay of Biscay in spring, ontogenic and diel vertical migrations have been proven to affect larval transport by favouring retention (Thiébaut et al., 1992; Queiroga et al., 2007). As recently suggested by North et al. (2008), vertical behaviour of weakly swimming larvae significantly altered dispersal kernels, transport success, and connectivity. During the major part of the larval life (i.e. the first 20 days), the mean depths of larvae subject to an ontogenic migration were close to the mean depths of passive particles because of their null vertical velocity. At the end of larval life, when particles had a negative swimming velocity, those particles were located closer to the bottom, inducing shorter dispersal distances. Even if swimming behaviour occurred during the last days of larval life, and even for small swimming velocities $\left(<1 \mathrm{~mm} \mathrm{~s}^{-1}\right)$, such an ontogenic migration significantly favoured self-retention and increased the total transport success. With diel vertical migration, particle mean depth varied with the hour of the day, with variations in depth amplitude caused by the variations of the vertical eddy diffusivity 
related to spring/neap tide cycles. Indeed, highest amplitudes were observed in neap tide (low vertical eddy diffusivity) because diel migrations prevailed over vertical mixing; on the contrary, lowest amplitudes were observed in spring tide (high vertical eddy diffusivity), because vertical mixing prevailed. In our study, diel vertical migration did not modify the direction of the larval transport, although such migration has been reported to affect transport direction when interacting with semi-diurnal tidal currents in the NW European continental shelf (Hill, 1994). Also, this behaviour did not alter the total transport success nor the self-retention, contrary to what has been observed in the case of upwelling systems (Queiroga et al., 2007) when diel vertical migration interacts with the upwelling/downwelling circulation. However, Garland et al. (2002) suggested that diel vertical migrations could permit competent larvae to test the bottom for settlement during the day, which could favour settlement success. Besides its effect on the dispersal distance, vertical larval behaviour mainly decreased the size of the variance ellipses by reducing inter-individual variability in the larval trajectories. In the future, species-specific applications of this Lagrangian model will need to take into account species-specific larval mortality, growth, and behaviour.

\subsection{Connectivity between the Bay of Biscay and the English Channel}

In relation with the transport patterns previously described, connectivity patterns indicated that larval exchanges mainly occurred within the three main spawning areas (i.e. Western English Channel, South Brittany and Central Bay of Biscay) and that self retention was high. The northern populations of the English Channel and the Ushant Sea were relatively isolated from the other populations whereas South Brittany and Central Bay of Biscay populations freely exchanged larvae. Nevertheless, larval transport and connectivity were observed between the Bay of Biscay and the English Channel populations for particular hydroclimatic conditions and biological traits. Connectivity occurred for a PLD of 4 weeks, and for spawning that occurred in March 2003 and 2004, April 2002 and 2003, and May 2001. This result is partly consistent with the observations of low salinity surface water (LSSW) intrusions from the Bay of Biscay in the western English Channel for three consecutive years (2002-2004), suggesting frequent northwards transport of plume waters in late winter (March-April) (Kelly-Gerreyn et al., 2006). LSSW intrusions in the English Channel were reported as a consequence of high river discharges and wind and tide conditions, with faster travel of LSSW under NE winds and better intrusion under spring tide (Kelly-Gerreyn et al., 2006). Afterwards, from early spring to summer, frontal structures are established in the Ushant Sea between mixed and stratified waters (Pingree et al., 1975). In early spring, two haline fronts have been reported in the Ushant Sea and at the entrance of the Douarnenez Bay (Morin et al., 1991), i.e. at the location of the two thermal fronts established later in summer (Mariette and Le Cann, 1985). These two frontal structures may act as barriers to dispersal (Le Fèvre, 1986), especially (1) from the Bay of Biscay to the western English Channel populations and (2) from the Douarnenez Bay population (population \#3) to the open sea. The high self-retention observed for the population of Douarnenez might also partly result from a bias due to the horizontal resolution of the model $(4 \mathrm{~km})$ given the narrow width of the entrance of the bay (less than $12 \mathrm{~km}$, represented by three grid cells in the model). In future work, models using a smaller horizontal resolution should be developed to test the role of the spatial gridding on dispersal and connectivity patterns (Guizien et al., 2006). In the Ushant Sea, Le Boyer et al. (2009) have reported northwards jet like structures and cyclonic frontal eddies that could either favour northwards larval transport or locally trap the larvae.
The transport of larval particles and connectivity from South Brittany to the English Channel require the concordance of several hydrodynamic and biological processes: (1) a larval release in the plume waters, which is likely for coastal invertebrates that spawn in late winter and early spring, (2) a northwestward along-shore transport of the plume waters, likely for spring meteorological conditions, (3) a northward transport through the Ushant Sea under the influence of transitory wind events, (4) an eastward reorientation of the plume waters to enter the English Channel under the influence of tidal residual currents, and (5) a planktonic larval duration long enough to ensure the transport by plume waters from the South Brittany to the English Channel populations.

Connectivity of marine invertebrate populations between the Bay of Biscay and the western English Channel is coherent with the phylogeographic patterns along the Brittany coasts described by Jolly et al. (2005) for the polychaete Pectinaria koreni. However, connectivity from the western English Channel to the Bay of Biscay population was never observed in our model runs, indicating that the Ushant Sea acts as a partly-permeable one-way barrier for connectivity: northwards larval exchanges are scarce, whereas southwards larval exchanges are unlikely. Moreover, the general lack of suitable habitats along the French coasts of the western English Channel for species inhabiting muddy fine sand sediments, could limit the connectivity of such species between the western and the eastern English Channel (Barnay et al., 2003). These findings are coherent with the description of the western English Channel as a transition zone between the temperate and cold-temperate biogeographical provinces (Cox and Moore, 2000; Dinter, 2001).

\section{Conclusions}

Invertebrate larval dispersal and connectivity was modeled between the Bay of Biscay and the western English Channel. Common life history characteristics of benthic invertebrates inhabiting fragmented habitats were used to simulate Lagrangian larval transport under realistic meteorological forcings. Our results highlighted the role played by the mesoscale seasonal variability of hydrodynamics on transport patterns and connectivity. At the temporal and spatial scale of larval life considered here, no significant year-to-year variations were observed in dispersal kernels. On the contrary, spawning month, spawning population, PLD, and larval vertical behaviour played major roles in dispersal kernel variability. Connectivity between South Brittany and western English Channel populations was reported but only under particular hydrodynamic conditions and for specific biological traits. As proposed by Gaylord and Gaines (2000) and Zacherl et al. (2003), biogeographical distributions of marine species depend not only on individual physiological tolerances but may partly rely on population processes including larval transport and recruitment success. The present study confirms that connectivity could mediate range limits of marine invertebrates in the North-East Atlantic according to the interactions between hydrodynamics and spawning period, PLD, or suitable habitat availability. The next step of this work would be to apply this model to specific invertebrate species, using species-specific biological traits (reproductive outputs of adult populations, larval mortality, larval growth and PLD variations, larval behaviour). Model results would then be confronted with in situ observations of larval distributions. Such modelling work also provides a useful tool to test several hypotheses on changes in connectivity and range limits in response to climate changes. Indeed, since water temperature increases are likely to induce earlier spawning and shorter PLD, such a bio-physical model can be used to assess the consequences of those two hypotheses on larval dispersal and connectivity patterns (Lett et al., 2010). 


\section{Acknowledgments}

The present study was financed by the French National Program EC2CO (Ecosphère Continentale et Côtière). S.-D. Ayata was supported by a PhD grant from the French Ministry of National Education and Research. The authors are grateful to Laure Noel for the English proofreading.

\section{References}

Aiken, C., Navarrete, S., Castillo, M., Castilla, J., 2007. Along-shore larval dispersal kernels in a numerical ocean model of the central Chilean coast. Marine Ecology Progress Series 339, 13-24.

Allain, G., Petitgas, P., Lazure, P., Grellier, P., 2007. Biophysical modelling of larval drift, growth and survival for the prediction of anchovy (Engraulis encrasicolus) recruitment in the Bay of Biscay (NE Atlantic). Fisheries Oceanography 16, 489-505.

Ayata, S., Ellien, C., Dumas, F., Dubois, S., Thiébaut, E., 2009. Modelling larval dispersal and settlement of the reef-building polychaete Sabellaria alveolata: role of hydroclimatic processes on the sustainability of biogenic reefs. Continental Shelf Research 29, 1605-1623.

Barnay, A.-S., Ellien, C., Gentil, F., Thiébaut, E., 2003. A model study on variations in larval supply: are populations of the polychaete Owenia fusiformis in the English Channel open or closed? Helgoland Marine Research 56, 229-237.

Byers, J., Pringle, J., 2006. Going against the flow: retention, range limits and invasions in advective environments. Marine Ecology Progress Series 313, 27 41.

Cabioch, L., 1968. Contribution à la connaissance des peuplements benthiques de la Manche Occidentale. Cahiers de Biologie Marine 5, 488-720.

Chia, F., Buckland-Nicks, J., Young, C., 1984. Locomotion of marine invertebrate larvae: a review. Canadian Journal of Zoology 62, 1205-1222.

Cowen, R., Sponaugle, S., 2009. Larval dispersal and marine population connectivity. Annual Review of Marine Science 1, 443-446.

Cowen, R., Lwiza, K., Sponaugle, S., Paris, C., Olson, D., 2000. Connectivity of marine populations: open or closed? Science 287, 857-859.

Cowen, R., Gawarkiewicz, G., Pineda, J., Thorrold, S., Werner, F., 2007. Population connectivity in marine systems: an overview. Oceanography 20, 14-21.

Cox, B., Moore, P., 2000. Biogeography: An Ecological and Evolutionary Approach. Blackwell Scientific Publications, London.

Dinter, W., 2001. In: Bonn, G., (Ed.), Biogeography of the OSPAR maritime area. Federal Agency for Nature Conservation.

Edwards, K.P., Hare, J.A., Werner, F.E., Seim, H., 2007. Using 2-dimensional dispersal kernels to identify the dominant influences on larval dispersal on continental shelves. Marine Ecology Progress Series 352, 77-87.

Garland, E. Zimmer, C., Lentz, S., 2002. Larval distributions in inner-shelf waters: the roles of wind-driven cross-shelf currents and diel vertical migrations. Limnology and Oceanography 47, 803-817.

Gaylord, B., Gaines, S., 2000. Temperature or transport? Range limits in marine species mediated solely by flow. American Naturalist 155, 769-789.

Glémarec, M., 1969. Les peuplements benthiques du plateau continental NordGascogne. Thèse de doctorat d'état. Faculté des Sciences de Brest.

Gómez-Gesteira, M., deCastro, M., Alvarez, I., Gómez-Gesteira, J.L., 2008. Coastal sea surface temperature warming trend along the continental part of the Atlantic arc (1985-2005). Journal of Geophysical Research 113, doi:10.1029/ 2007JC004315.

Guillou, J., 1980. Les peuplements de sables fins du littoral Nord-Gascogne. Thèse de 3ème cycle. Université de Bretagne Occidentale.

Guizien, K., Brochier, T., Duchêne, J., Koh, B., Marsaleix, P., 2006. Dispersal of Owenia fusiformis larvae by wind-driven currents: turbulence, swimming behaviour and mortality in a three-dimensional stochastic model. Marine Ecology Progress Series 311, 47-66.

Hill, A., 1994. Horizontal zooplankton dispersal by diel vertical migration in S2 tidal currents on the northwest European continental shelf. Continental Shelf Research 14, 491-506.

Hily, C., 1976. Ecologie benthique des Pertuis charentais. Thèse de 3ème cycle. Université de Bretagne Occidentale.

Houghton, R., 2002. Diapycnal flow through a tidal front: a dye tracer study on Georges Bank. Journal of Marine Systems 37, 31-46.

Hunter, J., Craig, P., Phillips, H., 1993. On the use of random walk models with spatially variable diffusivity. Journal of Computational Physics 106, 366-376.

Huret, M., Petitgas, P., Woillez, M., 2010. Dispersal patterns of anchovy (Engraulis encrasicolus) early life stages in the Bay of Biscay captured with a 3D hydrodynamical model and spatial indices. Progress in Oceanography 87 (14), 6-17.

Jolly, M., Jollivet, D., Gentil, F., Thiébaut, E., Viard, F., 2005. Sharp genetic break between Atlantic and English Channel populations of the polychaete Pectinaria koreni, along the north coast of France. Heredity 94, 23-32.

Jolly, M.T., Viard, F., Gentil, F., Thiébaut, E., Jollivet, D., 2006. Comparative phylogeography of two coastal polychaete tubeworms in the northeast Atlantic supports shared history and vicariant events. Molecular Ecology 15, 1814-1855.

Kelly-Gerreyn, B.A., Hydes, D.J., Jégou, A.M., Lazure, P., Fernand, L.J., Puillat, I., Garcia-Soto, C. 2006. Low salinity intrusions in the western English Channel. Continental Shelf Research 26, 1241-1257.
Kinlan, B., Gaines, S., 2003. A comparative analysis of dispersal scales in marine and terrestrial systems. Ecology 84, 2007-2020.

Koutsikopoulos, C., Le Cann, B., 1996. Physical processes and hydrological structures related to the Bay of Biscay anchovy. Scientia Marina 60, 9-19.

Kuebel Cervantes, B., Allen, J., Samelson, R., 2003. A modelling study of Eulerian and Lagrangian aspects of shelf circulation off Duck, North Carolina. Journal of Physical Oceanography 33, 2070-2092.

Lazure, P., Dumas, F., 2008. An external-internal mode coupling for a 3D hydrodynamical model for applications at regional scale (MARS). Advances in Water Resources 31, 233-250.

Lazure, P., Jégou, A.M., 1998. 3D modelling of seasonal evolution of Loire and Gironde plumes on Biscay Bay continental shelf. Oceanologica Acta 21, 165177

Lazure, P., Dumas, F., Vrignaud, C., 2008. Circulation on the Armorican shelf (Bay of Biscay) in autumn. Journal of Marine Systems 72, 218-237.

Lazure, P., Garnier, V., Dumas, F., Herry, C., Chifflet, M., 2009. Development of a hydrodynamic model of the Bay of Biscay: validation of hydrology. Continental Shelf Research 29, 985-997.

Le Boyer, A., Cambon, G., Daniault, N., Herbette, S., Le Cann, B., Marié, L., Morin, P. 2009. Observations of the Ushant tidal front in September 2007. Continental Shelf Research 29, 1026-1037.

Le Fèvre, J., 1986. Aspects of the biology of frontal systems. Advances in Marine Biology 23, 163-299.

Legendre, P., Legendre, L., 1998. Numerical Ecology, 2nd English ed. Elsevier Science BV, Amsterdam.

Lett, C., Ayata, S., Huret, M., Irisson, J., 2010. Biophysical modelling to investigate the effects of climate change on marine populations dispersal and connectivity. Progress in Oceanography 87 (1-4), 106-113.

Levin, L., 2006. Recent progress in understanding larval dispersal: new directions and digressions. Integrative and Comparative Biology 46, 282-297.

Lyard, F., Lefevre, F., Letellier, T., Francis, O., 2006. Modelling the global ocean tides: modern insights from FES2004. Ocean Dynamics 56, 394-415.

Mariette, V., Le Cann, B., 1985. Simulation of the formation of the Ushant frontal systems. Continental Shelf Research 4, 637-660.

Marinone, S., Ulloa, M., Parés-Sierra, A., Lavín, M., Cudney-Bueno, R., 2008. Connectivity in the northern gulf of California from particle tracking in a three-dimensional numerical model. Journal of Marine Systems 71, 149-158.

Metaxas, A., Saunders, M., 2009. Quantifying the "bio-" components in biophysical models of larval transport in marine benthic invertebrates: advances and pitfalls. Biological Bulletin 216, 257-272.

Morin, P., Le Corre, P., Marty, Y., L'Helguen, S., 1991. Evolution printanière des éléments nutritifs et du phytoplancton sur le plateau continental Armoricain (Europe du nord-ouest). Oceanologica Acta 14, 263-279.

North, E.W., Hood, R.R., Chao, S., Sanford, L.P., 2006. Using a random displacement model to simulate turbulent particle motion in a baroclinic frontal zone: a new implementation scheme and model performance tests. Journal of Marine Systems 60, 365-380.

North, E.W., Schlag, Z., Hood, R.R., Li, M., Zhong, L., Gross, T., Kennedy, V.S., 2008. Vertical swimming behavior influences the dispersal of simulated oyster larvae in a coupled particle-tracking and hydrodynamic model of Chesapeake bay. Marine Ecology Progress Series 359, 99-115.

O’Connor, M., Bruno, J., Gaines, S., Halpern, B., Lester, S., Kinlan, B., Weiss, J., 2007. Temperature control of larval dispersal and the implications for marine ecology, evolution, and conservation. Proceedings of the National Academy of Sciences of the USA $104,1266-1271$.

Okubo, A., 1994. The role of diffusion and related physical processes in dispersal and recruitment of marine populations. In: Sammarco, P.W., Heron, M.L. (Eds.), The Bio-Physics of Marine Larval Dispersal. American Geophysical Union, Washington, DC, pp. 5-32.

Olive, P., 1995. Annual breeding cycles in marine invertebrates and environmental temperature probing the proximate and ultimate causes of reproductive synchrony. Journal of thermal biology 20, 79-90.

Pedersen, O., Aschan, M., Rasmussen, T., Tande, K., Slagstad, D., 2003. Larval dispersal and mother populations of Pandalus borealis investigated by a Lagrangian particle tracking model. Fisheries Research 65, 173-190.

Pineda, J., Hare, J., Sponaugle, S., 2007. Larval transport and dispersal in the coastal ocean and consequences for population connectivity. Oceanography 20, 22-39.

Pingree, R., Le Cann, B., 1989. Celtic and Armorican slope and shelf residual currents. Progress in Oceanography 23, 303-338.

Pingree, R., Maddock, L., 1977. Tidal residual in the English Channel. Journal of the Marine Biological Association of the United Kingdom 57, 339-354.

Pingree, R., Pugh, P., Holligan, P., Forster, G., 1975. Summer phytoplankton blooms and red tides along the tidal fronts in the approaches of the English Channel. Nature 258, 672-677.

Planque, B., Beillois, P., Jégou, A.M., Lazure, P., Petitgas, P., Puillat, I., 2003. Largescale hydroclimatic variability in the Bay of Biscay: the 1990s in the context of interdecadal changes. ICES Marine Science Symposium 219, 61-70.

Proehl, J., Lynch, D., McGillicuddy, D., Ledwell, J., 2005. Modeling turbulent dispersion on the North Flank of Georges Bank using Lagrangian particle methods. Continental Shelf Research 25, 875-900.

Puillat, I., Lazure, P., Jégou, A.M., Lampert, L., Miller, P., 2004. Hydrographical variability on the French continental shelf in the Bay of Biscay during the 1990s. Continental Shelf Research 24, 1143-1163.

Puillat, I., Lazure, P., Jégou, A.M., Lampert, L., Miller, P., 2006. Mesoscale hydrological variability induced by northwesterly wind of the French continental shelf of the Bay of Biscay. Scientia Marina 70, 15-26. 
36

S.-D. Ayala et al./Progress in Oceanography 87 (2010) 18-36

Queiroga, H., Cruz, T., dos Santos, A., Dubert, J., González-Gordillo, J., Paula, J., Peliz, Á., Santos, A., 2007. Oceanographic and behavioural processes affecting invertebrate larval dispersal and supply in the western Iberia upwelling ecosystem. Progress in Oceanography 74, 174-191.

R Development Core Team, 2005. R: a language and environment for statistical computing, reference index version 2.6.2. $\mathrm{R}$ foundation for statistical computing, Vienna, Austria. ISBN 3-900051-07-0 <http://www.r-project.org>.

Reitzel, A., Miner, B., McEdward, L., 2004. Relationships between spawning date and larval development time for benthic marine invertebrates: a modelling approach. Marine Ecology Progress Series 280, 13-23.

Reynaud, T., Legrand, P., Mercier, H., Barmier, B., 1998. A new analysis of hydrographic data in the Atlantic and its application to an inverse modelling study. International WOCE Newsletter 32, 29-31.

Ross, O.N., Sharples, J., 2004. Recipe for 1-D Lagrangian particle tracking models in space-varying diffusivity. Limnology and Oceanography: Methods 2, 289-302.

Saloon, J., Breton, M., 1993. An atlas of long-term currents in the Channel. Oceanologica Anta 16, 439-448.

Shanks, A., Larger, J., Brink, L., Brubaker, J., Hooff, R., 2002. Observations on the distribution of meroplankton during a downwelling event and associated intrusion of the Chesapeake bay estuarine plume. Journal of Plankton Research 24, 391-416.
Shanks, A., McCulloch, A., Miller, J., 2003. Topographically generated fronts, very nearshore oceanography and the distribution of larval invertebrates and holoplankters. Journal of Plankton Research 25, 1251-1277.

Suchanek, T.H., Geller, J.B., Kreiser, B.R., Mitten, J.B., 1997. Zoogeographic distributions of the sibling species Mytilus galloprovincialis and M. trossulus (Bivalvia: Mytilidae) and their hybrids in the north Pacific. Biological Bulletin 193, 187-194.

Thiébaut, E., Dauvin, J.C., Lagadeuc, Y., 1992. Transport of Owenia fusiformis larvae (Annelida: Polychaeta) in the Bay of Seine. I. Vertical distribution in relation to water column stratification and ontogenic vertical migration. Marine Ecology Progress Series 80, 29-39.

Treml, E., Hatpin, P., Urban, D., Pratson, L., 2008. Modeling population connectivity by ocean currents, a graph-theoretic approach for marine conservation. Landscape Ecology 23, 19-36.

Visser, A.W., 1997. Using random walk models to simulate the vertical distribution of particles in a turbulent water column. Marine Ecology Progress Series 158, 275-281.

Xie, H., Lazure, P., Gentian, P., 2007. Small scale retentive structures and Dinophysis. Journal of Marine Systems 64, 173-188.

Zacherl, D., Gaines, S., Lonhart, S., 2003. The limits to biogeographical distributions: insights from the northward range extension of the marine snail, Kelletia kelletii. Journal of Biogeography 30, 913-924. 